\title{
CHEMBIOCHEM
}

DOI: 10.1002/cbic.200900779

\section{The Future of Aminoglycosides: The End or Renaissance?}

Jacob L. Houghton, ${ }^{[a, c]}$ Keith D. Green, ${ }^{[c]}$ Wenjing Chen ${ }^{[b, c]}$ and Sylvie GarneauTsodikova $*[a, b, c]$

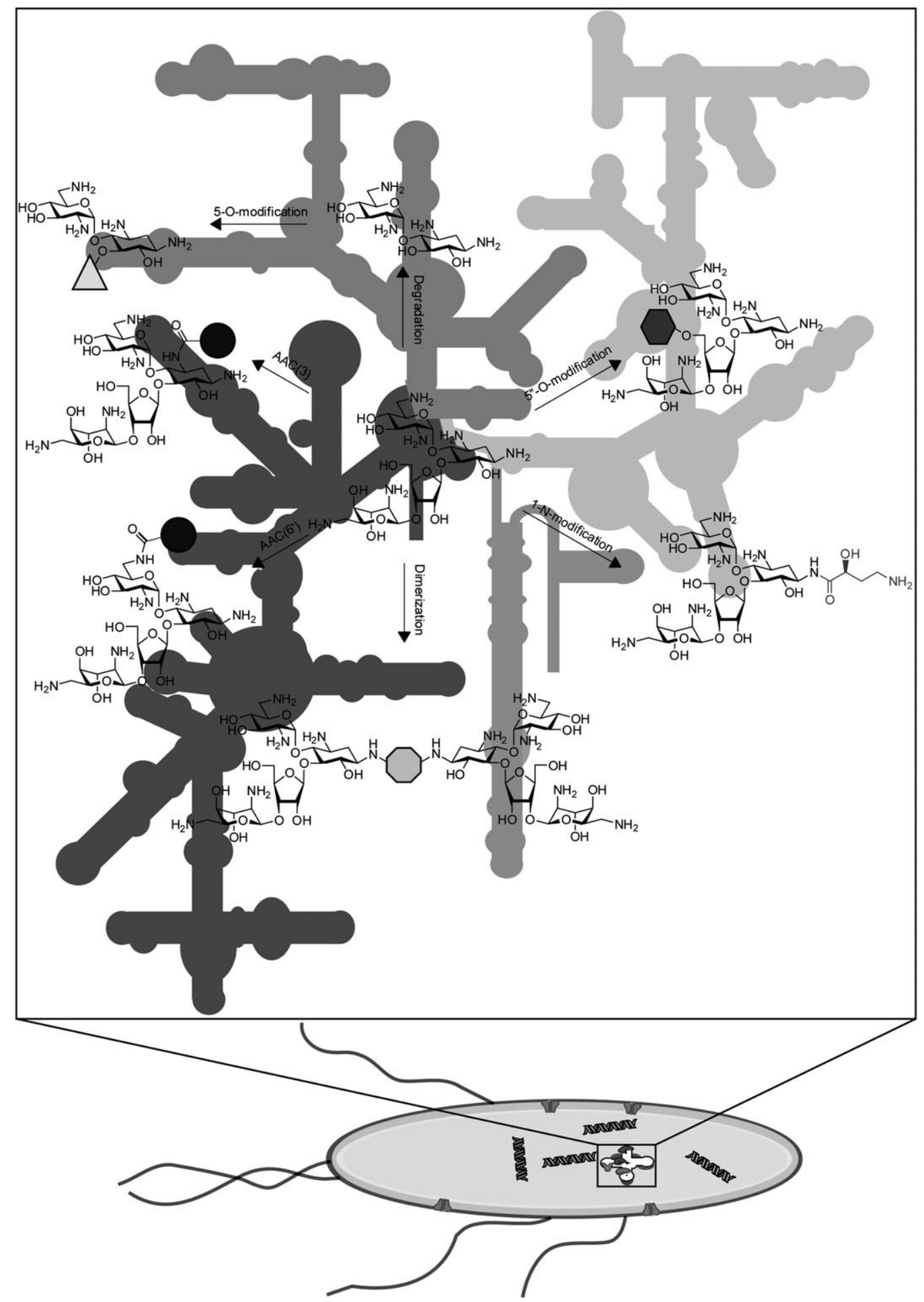


Although aminoglycosides have been used as antibacterials for decades, their use has been hindered by their inherent toxicity and the resistance that has emerged to these compounds. It seems that such issues have relegated a formerly front-line class of antimicrobials to the proverbial back shelf. However, recent advances have demonstrated that novel aminoglyco- sides have a potential to overcome resistance as well as to be used to treat HIV-1 and even human genetic disorders, with abrogated toxicity. It is not the end for aminoglycosides, but rather, the challenges faced by researchers have led to ingenuity and a change in how we view this class of compounds, a renaissance.

\section{Introduction}

Since the discovery of the first major antibiotic, penicillin, in 1928 a multitude of antibiotics including aminoglycosides, $\beta$ lactams, fluoroquinolones, and others have been discovered and applied clinically for the treatment of one of the many growing number of multidrug-resistant strains of bacteria. Aminoglycosides (Figure 1) in particular are being extensively examined to find new compounds or derivatives that might overcome the existing resistant pathogens as well as prevent or slow the development of novel resistant pathogens.

Aminoglycosides were first established as antibiotics in the 1940 s with the discovery of streptomycin and are still widely used worldwide. Due to their heavy use in treating bacterial infections, many strains of bacteria have become resistant to normal doses of aminoglycosides through the production and use of aminoglycoside-modifying enzymes and other methods. To side-step the issue of antibiotic resistance, many scientists have taken on the intricate task of synthesizing aminoglycoside derivatives, including aminoglycoside dimers and conjugates with other biomolecules. Efforts aiming to create better aminoglycosides have used several strategies including chemoenzymatic modification and coupling of antibiotics, both aminoglycosides as well as other classes of drugs, by synthetic or semisynthetic methods.

In this review, current and potential applications of aminoglycosides as antibacterials, antivirals/HIV, and for the treatment of genetic diseases, as well as the mechanisms underlying those actions are discussed. Included are examples of current hurdles and/or advancements in the respective areas of research. We focus on some traditional concerns associated with aminoglycosides, including those related to the development of resistance, and the toxicity experienced upon administration, as well as the difficulties surrounding the development of improved aminoglycosides. The discussion of the problems facing aminoglycoside treatment is followed by a description of some current strategies aiming to alleviate the problems: primarily the development of novel aminoglycoside compounds and novel chemoenzymatic methods used in the development and screening processes. We believe that the promise of aminoglycosides in the near future should inspire optimism in researchers and those who might someday soon benefit from the exciting work presently being conducted around the world.

\section{Aminoglycosides: Their Use and Mechanisms of Action}

\subsection{Aminoglycoside antibiotics}

Since the discovery of streptomycin in the 1940s, aminoglycosides have enjoyed widespread application as chemotherapeutic agents in the treatments of many types of bacterial infections, including both Gram-positive and Gram-negative pathogens. ${ }^{[1]}$ The antibacterial mechanism of action of aminoglycosides has been well characterized, and it was discovered in the late 1980s that aminoglycosides' molecular target is the $16 \mathrm{~S}$ rRNA subunit of the $30 \mathrm{~S}$ bacterial ribosome. ${ }^{[2]}$ Although alternative modes of binding have been seen with various aminoglycoside derivatives, ${ }^{[3]}$ the general interactions of aminoglycosides with three unpaired adenine residues in the decoding loop displaces noncomplementary adenines and locks them into a so-called "flipped-out" orientation similar to that observed during mRNA decoding. ${ }^{[4-7]}$ Structural examples of these interactions from crystallographic or modeling studies are shown in Figure 2, which depicts tobramycin, geneticin, amikacin, and paromomycin in complex with A-site oligonucleotides. ${ }^{[8-11]}$ These interactions reduce the fidelity of normal translational processes by reducing the ability of the ribosome to discriminate between the proper mRNA-tRNA complexes; this leads to the accumulation of truncated or nonfunctional proteins in the bacterial cells, and eventually to cell death. For a thorough structure-based analysis of the interactions of aminoglycosides with the decoding A-site see the recent review by François et al. ${ }^{[12]}$

Another contribution to the antibacterial activity of aminoglycosides, exemplified by paromomycin, comes from their ability to interfere with translocation through the stabilization of the 70 S subunit. In 2008, Kaji and co-workers showed that paromomycin inhibits the anti-association activity of translation initiation factor 3 (IF3), which is involved in the disassembly reaction of ribosomal complexes, post-termination. ${ }^{[13]}$ It does so by strengthening the interactions between the $50 \mathrm{~S}$

[a] J. L. Houghton, Dr. S. Garneau-Tsodikova

Department of Medicinal Chemistry in the College of Pharmacy

University of Michigan, 210 Washtenaw Avenue, Ann Arbor, MI 48109 (USA)

Fax: (+1) 734-615-5521

E-mail:sylviegt@umich.edu

[b] W. Chen, Dr. S. Garneau-Tsodikova

Chemical Biology Doctoral Program, University of Michigan

210 Washtenaw Avenue, Ann Arbor, MI 48109 (USA)

[c] J. L. Houghton, Dr. K. D. Green, W. Chen, Dr. S. Garneau-Tsodikova

Life Sciences Institute, University of Michigan

210 Washtenaw Avenue, Ann Arbor, MI 48109 (USA) 
Jacob Houghton majored in chemistry at Carleton College, Minnesota (BA 2007). During the Summer of 2006 he worked in the laboratory of Dr. Leonard MacGillivray at the University of lowa where he studied template-controlled solid-state synthesis. Jacob is now a PhD candidate in the laboratory of Prof. Sylvie Garneau-Tsodikova studying the development of novel aminoglycoside antibiotics as well as the synthesis and testing of novel compounds for the treatment of Alzheimer's disease.

Keith D. Green majored in chemistry at Michigan Technological University (BS 2003). He obtained his PhD in chemistry in 2008 at Wayne State University where he explored the cosubstrate promiscuity of protein kinases in the laboratory of Prof. Mary Kay Pflum. Now a postdoctoral fellow in Prof. Sylvie Garneau-Tsodikova's laboratory he is developing new tools for combinatorial biosynthesis and the production of novel aminoglycoside antibiotics.

Wenjing Chen majored in biochemistry and biological chemistry at the University of Nottingham, UK (BSC 2006, MSC 2007), where she studied the biophysical properties of the endopeptidase domain of lysostaphin in the laboratory of Prof. Neil Thomas. She moved to the USA in 2007 and is now a PhD candidate in the laboratory of Prof. Sylvie Garneau-Tsodikova studying aminoglycoside-modifying enzymes and developing novel aminoglycoside antibiotics.

Sylvie Garneau-Tsodikova majored in chemistry at the Université Laval, Québec City (BSc 1995, MSc 1997). She obtained her PhD in chemistry in 2003 at the University of Alberta where she studied new antimicrobial agents acting on bacterial cell walls in the laboratory of Prof. John C. Vederas. As a postdoctoral fellow in Prof. Christopher T. Walsh's laboratory at Harvard Medical School she studied halogenation and pyrrole formation during the biosynthesis of various natural products. In 2006, she joined the University of Michigan as the John G. Searle Assistant Professor of Medicinal Chemistry at the College of Pharmacy and the Life Sciences Institute.

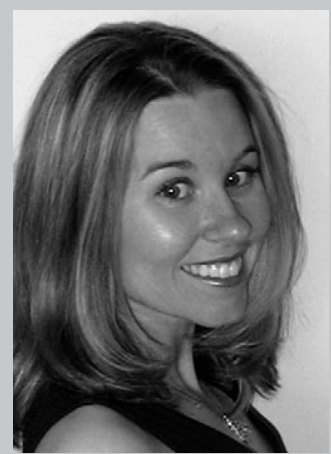

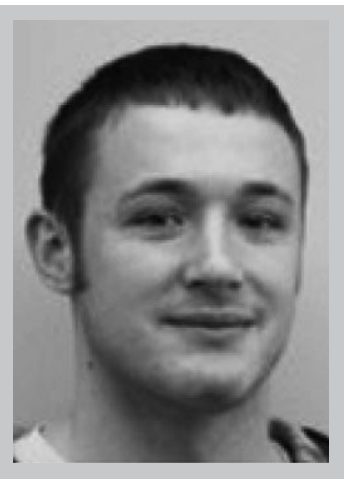
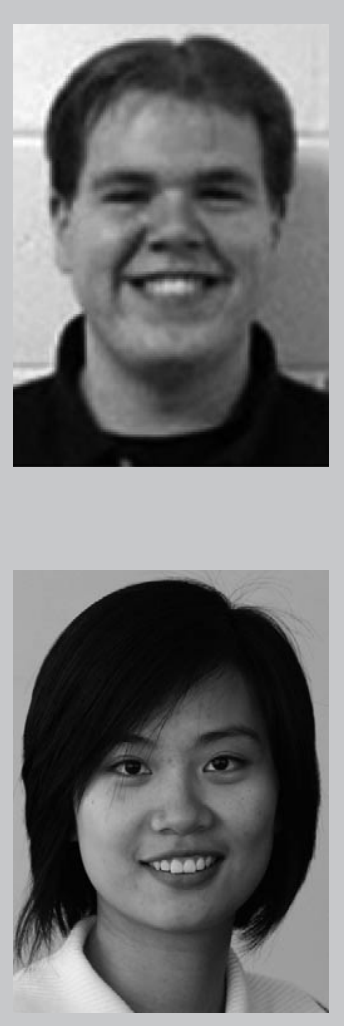

and 305 subunits, thus stabilizing the 705 complex, which leads to a loss of internal mobility and ability to properly translocate tRNAs. Recent studies have shown that this activity might arise from the aminoglycosides' ability to interact with specific sites of the $16 \mathrm{~S}$ rRNA. ${ }^{[14]}$

It has been shown that there are two primary types of interactions that facilitate the recognition and binding of aminoglycosides to their targets. The most significant contribution comes from electrostatic interactions that occur between the positively charged amino groups of the aminoglycoside and the negatively charged phosphate backbones of the RNA target. ${ }^{[15]}$ The other contribution comes from hydrogen bonds formed between the multiple amino and hydroxyl groups of both the RNA bases and aminoglycosides. ${ }^{[12,16-18]}$ The intricate network of electrostatic contacts and hydrogen bonds between the RNA and aminoglycosides produces a very tightly bound complex prone to decreased translational fidelity.

For example, the 2-deoxystreptamine (2-DOS) ring (ring II) of paromomycin has hydrogens binding to U1406, U1495, and G1494 of the $16 \mathrm{~S}$ bacterial RNA. Ring I, depending on the substitution pattern of the particular aminoglycoside, has been shown to bind to a number of ribosomal nucleobases including A1408, A1493, A1492, and G1491. ${ }^{[17,18]}$ These two rings are common amongst most aminoglycosides. ${ }^{[19]}$ There are no significant interactions between ring III and the RNA. The additional rings attached to the 5- or 6-position of the pseudostreptamine ring might have more effect on an aminoglycoside's specificity. Crystal structures of kanamycin $A$, neamine, gentamicin $\mathrm{C} 1 \mathrm{~A}$, ribostamycin, lividomycin, neomycin $\mathrm{B}$, and tobramycin with oligonucleotides including the decoding Asite of bacterial ribosomes revealed that not only are rings I and II essential for the recognition of the above aminoglycosides, but they are also conserved and sequence specific. ${ }^{[12]}$

The selectivity of aminoglycosides towards the bacterial ribosomal subunit over the analogous human subunit is due to fundamental differences in the respective nucleotide sequences, which leads to lower affinity of the aminoglycosides for the human ribosome. ${ }^{[20]}$ The permeability of the cells is also a critical factor in the selectivity of aminoglycosides towards bacterial cells. The polycationic nature of the aminoglycosides prevents the efficient uptake of the compounds in most eukaryotic cells, whereas the polycationic properties enhance the agents' uptake in many bacterial cells due to the presence of energy-dependent transport pathways that utilize the membrane-bound electron transporters. ${ }^{[21,22]}$

An increasing number of biochemical and structural studies have correlated the incorporation of the $\gamma$-aminohydroxybutyric acid (AHB) at the N1-position of the 2-DOS ring, common in many aminoglycosides, with an improved antibacterial profile. Additionally, crystallographic studies of several AHB-containing aminoglycosides have shown that the AHB functionality makes additional direct contacts with the ribosomal A-site, leading to higher binding affinities. ${ }^{[10,23]}$ Interestingly, the acyl moiety lowers the $\mathrm{p} K_{\mathrm{a}}$ of the $\mathrm{N} 1$ nitrogen atom, and this alteration of the $\mathrm{N} 1$ nitrogen of compounds such as amikacin, butirosin $\mathrm{B}$, and others, significantly enhances the binding of ring II to RNA. Additionally, the ammonium on the terminus of the AHB 


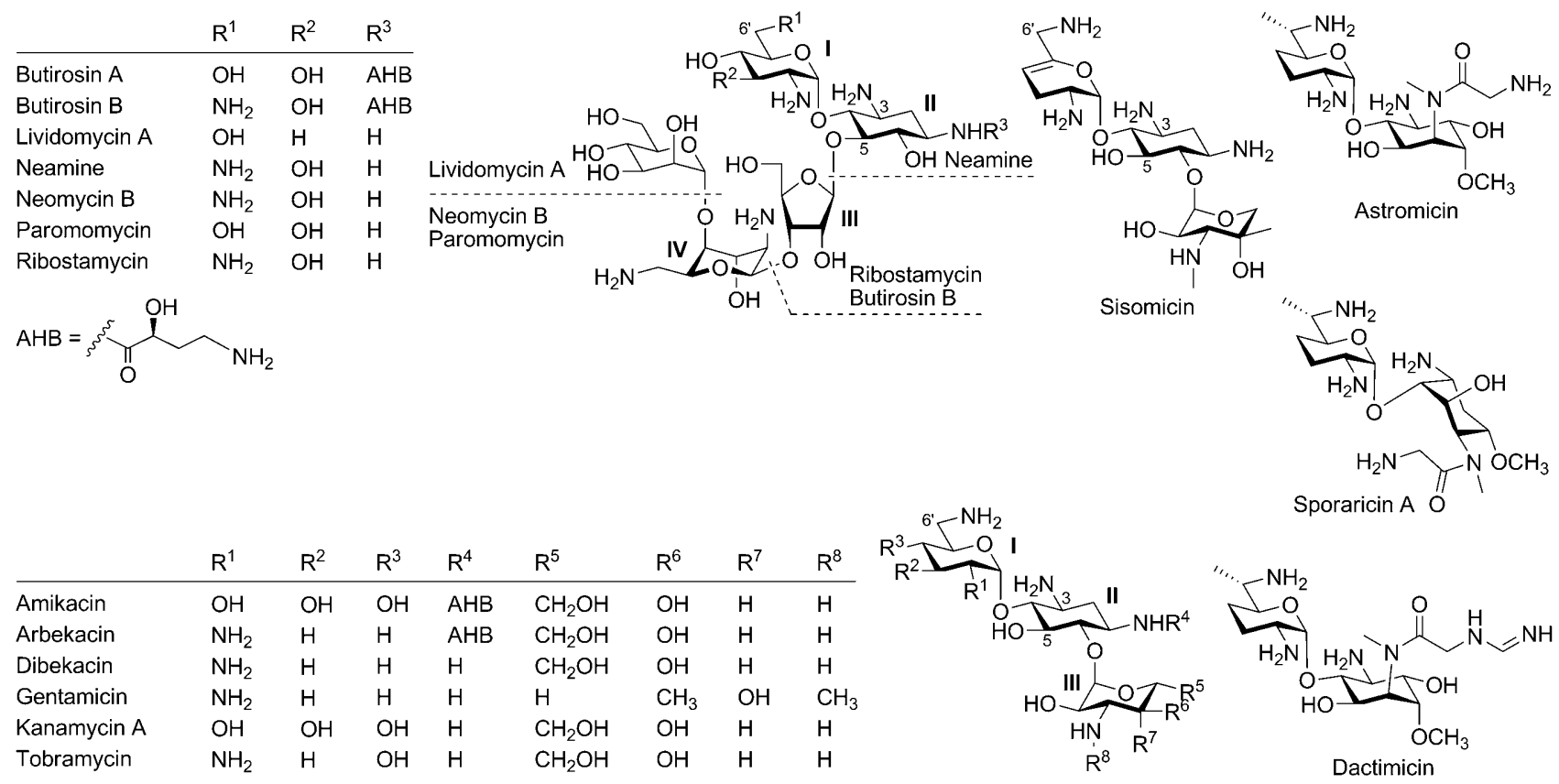

Figure 1. Chemical structures of natural and synthetic aminoglycosides.
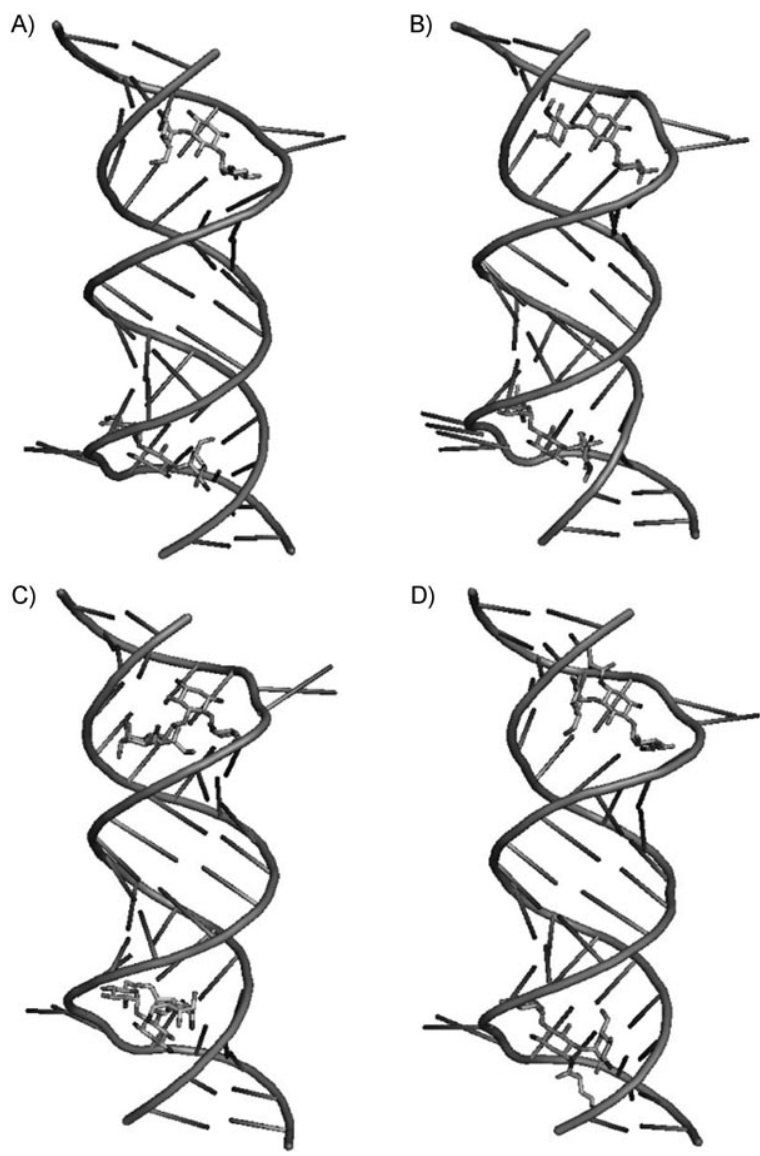

Figure 2. Structures of $16 \mathrm{~S}$ oligonucleotides mimicking the bacterial decoding A-site with A) tobramycin, B) geneticin, and C) amikacin bound. Also shown is D) the crystal structure of paromomycin docked into a bacterial Asite oligonucleotide. These images illustrate the "flipped-out" conformation of the residues displaced upon binding of aminoglycosides to the decoding A-site, which is the basis of the compounds' antibacterial activity. group provides another favorable interaction with a backbone phosphate. ${ }^{[24]}$ As a result of these observations, current strategies for increasing the antibacterial activity of aminoglycosides involve the incorporation of AHB or analogous functionalities to the scaffold of known aminoglycosides as well as synthetic and semi-synthetic analogues, a strategy that has produced results and shown enormous promise.

\subsection{Aminoglycosides' antiviral and anti-AIDS activity}

An exciting area of aminoglycoside research is the application of aminoglycoside-based compounds in the treatment of HIV, as over the past few decades their efficacy against HIV-1 has become more widely realized. It has been shown that aminoglycosides and aminoglycoside derivatives/conjugates are capable of targeting many steps in the HIV life cycle, and the development of compounds that show specificity towards a particular target has become the goal of many research efforts in recent years (Figure 3). Another exciting application for aminoglycosides that has recently come to light is their ability to induce the production of retrocyclins; this shows promise towards the development of aminoglycoside-based compounds for HIV prevention. ${ }^{[25]}$

One well-studied class of aminoglycoside compounds for the treatment of HIV is the aminoglycoside-arginine conjugates (AArC) and aminoglycoside-polyarginine conjugates (APArC). ${ }^{[26,27]}$ These compounds are particularly exciting because of their ability to target several of the crucial processes of the viral life cycle. As illustrated in Figure 3, the targets include multiple receptors or intermediates involved in the entry of HIV-1 to the host cells such as the glycoprotein-120 (gp120)-cluster of differentiation 4 (CD4) binding, gp120-CXC chemokine receptor 4 (CXCR4) binding, and gp41 hairpin for- 


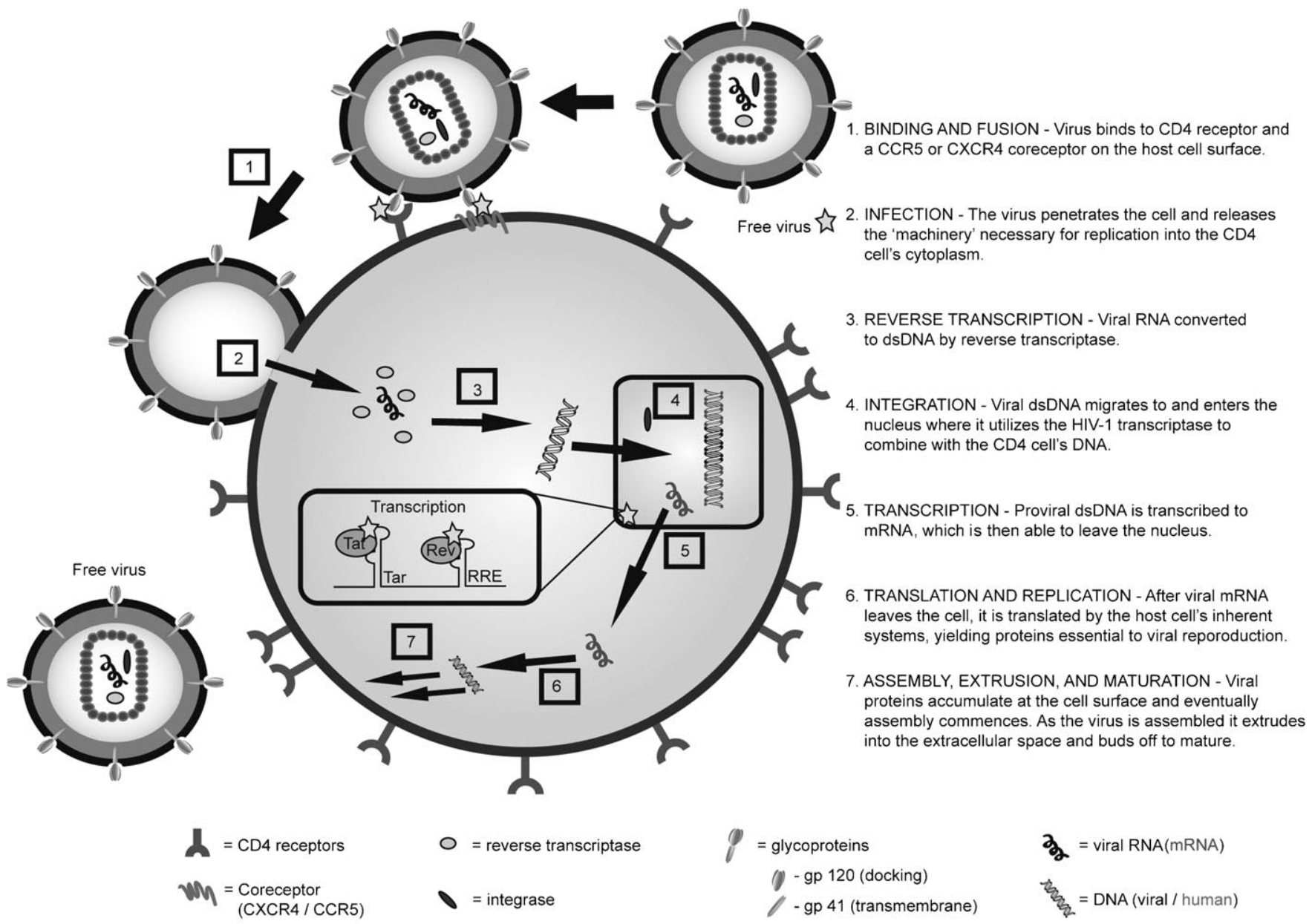

Figure 3. Depiction of the critical steps of viral reproduction inhibited by aminoglycosides or aminoglycoside derivatives, which are indicated by a star.

mation. The later stages are affected through interaction with regulatory RNAs, namely the HIV-1 Tat-responsive element (TAR) and HIV-1 Rev responsive element (RRE). ${ }^{[2]}$ Although aminoglycosides show promise for targeting HIV-1 TAR, studies have also pointed out the flexibility of the aminoglycosideTAR interaction, evidenced by TAR's strong interactions with a diverse collection of aminoglycosides and analogous compounds. ${ }^{[28,29]}$ Due to the pliability of these interactions, TAR is an inherently less selective target relative to the ribosomal Asite, and, consequently, the design of target-selective compounds is rather difficult. For a thorough review of the mechanisms of these compounds towards the various life processes of HIV-1, see Lapidot et al. ${ }^{[26]}$

Aminoglycosides also target the HIV-1 dimerization initiation site (DIS), which is responsible for initiating genome dimerization by forming a loop-loop complex (or "kissing-complex"), a vital step in the replication cycle. Crystal structures have shown that the HIV-1 DIS loop-loop complex is similar to the 16S A-site, which explains the strong affinity of several aminoglycosides for the DIS. ${ }^{[30]}$ The DIS specifically binds 4,5-disubstituted 2-DOS aminoglycosides such as neomycin B as well as the 4-monosubstituted apramycin, which contains a bicyclic moiety. ${ }^{[31]}$
Other types of aminoglycoside derivatives have also been tested against various HIV targets, including series of homoand heterodimers of kanamycin A, neomycin B, and tobramycin as well as some naphthalene-based diimide-conjugated bis-aminoglycoside compounds. These compounds were tested for their ability to bind rRNA A-sites and HIV-1 RRE (Section 4.2, Figure 11). ${ }^{[32,33]}$ Subsequently, series of neamine dimers as well as a series of nucleobase-aminoglycoside conjugates have shown the ability to inhibit TAR-Tat binding (Section 4.2 Figure 12 and Section 4.3 Figure 14). ${ }^{[28,34]}$

Guanidinoneomycin B, a compound recently reported by Butcher and co-workers, has been demonstrated to bind to an RNA helix from the HIV-1 frameshift site, interfering with the -1 ribosomal frame-shift between the gag and pol reading frames, which is required for the expression of the full complement of HIV-1 enzymes. ${ }^{[35,36]}$

Another possible mechanism of action of aminoglycosides was recently suggested by Tor and co-workers, who demonstrated various aminoglycosides' abilities to cause RNA cleavage upon binding. ${ }^{[37]}$ It is thought that binding might cause enough distortion in the RNA backbone to make it susceptible to intramolecular transesterification. Cleavage was observed at particular nucleobases in minimized versions of the A-site and 
HIV-1 TAR, which demonstrated the most pronounced cleavage of the RNA.

Aminoglycosides' ability to induce premature termination codon (PTC) read-through has been demonstrated in many systems as a possible treatment for genetic diseases (Section 2.3), but the possibility of additional benefits in the prevention of HIV-1 has also been reported. Defensins are small antimicrobial peptides found in eukaryotes that protect the host from a wide spectrum of pathogens including bacteria, fungi, and viruses. ${ }^{[25]}$ The $\theta$-defensins, such as retrocyclin, protect against infection of HIV-1 in Old World monkeys, but not in humans. Humans do not express defensins due to a $100 \%$ conserved PTC, which is believed to have arisen over seven million years ago. In 2009, Cole and co-workers reported that not only could these ancient genes be "reawakened", but also that it is possible to induce the production of retrocyclin- 1 by using aminoglycosides to read-through the PTCs. ${ }^{[25]}$ The authors highlight that viruses have evolved in the absence of the selective pressures previously exhibited by the retrocyclins, and thus, the ability to revive the production of these molecules could also revive the immune system's ability to prevent or limit the damage induced by viral infections.

These studies demonstrate the promise of aminoglycosides in the future not only as antibacterial treatments, but also as incredibly versatile agents in the treatment, and possibly prevention of HIV-1. ${ }^{[25]}$ A plethora of aminoglycosides has shown a variety of very interesting and promising activities. Compared to the studies of aminoglycosides as antibiotics, many of these are still in their infancy; this only makes the future that much more promising for aminoglycosides as a treatment for HIV.

\subsection{Aminoglycosides in the treatment of genetic diseases}

Although the scientific community has scrupulously investigated the efficacy of aminoglycosides as antibiotics for over 60 years, their potential in the treatment of human genetic diseases was not realized until more recently. Nearly 20 years after the discovery of streptomycin, it was discovered that aminoglycosides are able to suppress PTCs and restore full-length protein production in Escherichia coli. ${ }^{[38]}$ PTCs, often the result of base pair insertion, deletion, or substitutions, generally lead to the production of incorrectly truncated, nonfunctional proteins (Figure 4). In humans, PTCs have been linked to over 1800 genetic disorders and, consequently, the suppression of PTCs is a viable and extremely attractive strategy in the treatment of many genetic disorders. ${ }^{[39]}$

The potential of PTC suppression in mammalian cells was first demonstrated by the ability of gentamicin to suppress PTCs resulting from common mutations in the cystic fibrosis transmembrane conductance regulator (CFTR). These studies investigated the ability of the aminoglycoside gentamicin to suppress PTCs, and found that it was indeed capable of suppressing PTCs in CFTR, allowing for the production of functional proteins. ${ }^{[40,41]}$ Subsequent studies of aminoglycosides such as gentamicin, tobramycin, and amikacin showed a dose-dependent increase in the levels of full-length proteins relative to the truncated proteins produced by PTCs, suggesting that ami-
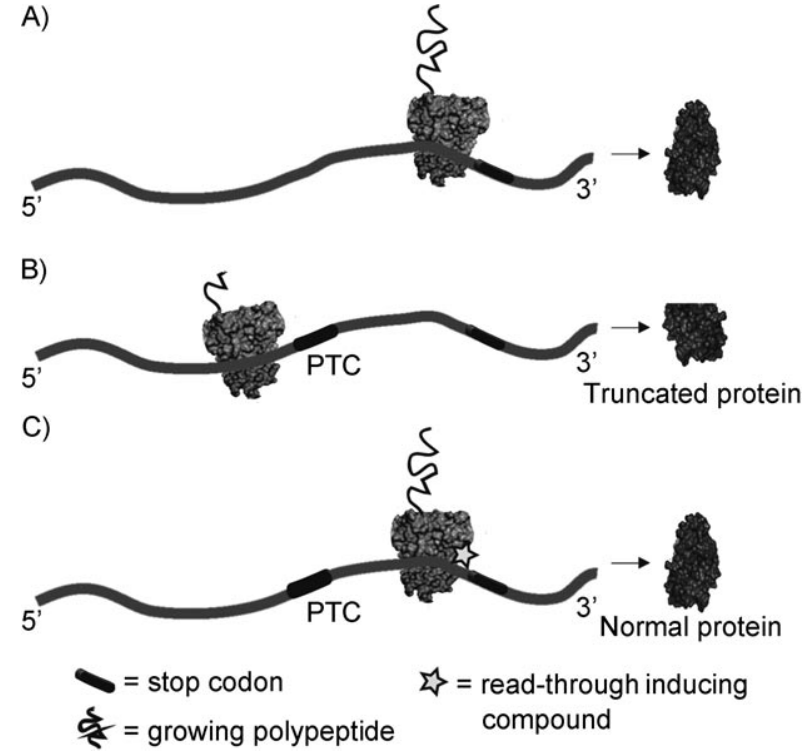

Figure 4. A comparison of the A) normal translation process leading to functional protein, B) translation which is interrupted by a premature termination codon (PTC) leading to a truncated nonfunctional protein, and C) translation process that was restored by a read-through-inducing compound such as an aminoglycoside.

noglycosides could prove effective in suppressing PTCs implicated in other genetic disorders. ${ }^{[42]}$ Additionally, recent studies on the nonaminoglycoside drug PTC124 (Ataluren ${ }^{\circledR}$ ), have provided a proof of concept in this field and shown incredible promise in clinical trials as a treatment for PTC-related genetic disorders. ${ }^{[43]}$ For a thorough review of recent studies on aminoglycosides and other drugs targeting nonsense mutations in genetic diseases, see Rowe and Clancy's recent review. ${ }^{[4]}$

In 2009, Baasov and co-workers reported the development of a novel aminoglycoside derivative (NB54) with better readthrough efficiency as well as decreased toxicity compared to gentamicin. ${ }^{[45]}$ The compound was tested in vitro against DNA fragments that mimic genes with disease-causing nonsense mutations. NB54 demonstrates enhanced PTC suppression against genes representing those implicated in conditions such as Duchenne's muscular dystrophy, Hurler syndrome, and cystic fibrosis. One concern that arises when considering treatment of genetic diseases with aminoglycosides is the toxicity associated with nonspecific binding. However, this study highlights the feasibility and promise of designing aminoglycosides with enhanced target specificity and abrogated toxicity. ${ }^{[45]}$

\section{Problems Associated with Aminoglycosides}

Three major problems associated with the use of aminoglycosides are bacterial resistance, toxicity, and the complexity associated with their chemical syntheses. The toxicity experienced upon administration of aminoglycosides is usually nephrotoxicity or ototoxicity, but occasionally neuromuscular blockage or hypersensitivity reactions. Bacterial resistance to aminoglycosides, resulting from intensive clinical use, is becoming increas- 
ingly prevalent worldwide and this phenomenon in particular presents a significant threat to public health.

\subsection{Resistance}

There are three mechanisms of bacterial resistance to aminoglycosides: 1) the reduction of the intracellular concentration of aminoglycosides due to alteration of the bacterial outer membrane, decreasing drug transport into the cell and/or increasing the activity of active efflux systems, 2) the alteration of the 16S RNA of bacterial $30 \mathrm{~S}$ ribosomal subunit by mutation or methylation of the aminoglycoside binding site, and 3) the deactivation of aminoglycosides by $\mathrm{N}$-acetylation, O-nucleotidylation, or O-phosphorylation (Figure 5). More than one of the above mechanisms can be simultaneously active, leading to complex resistance mechanisms.

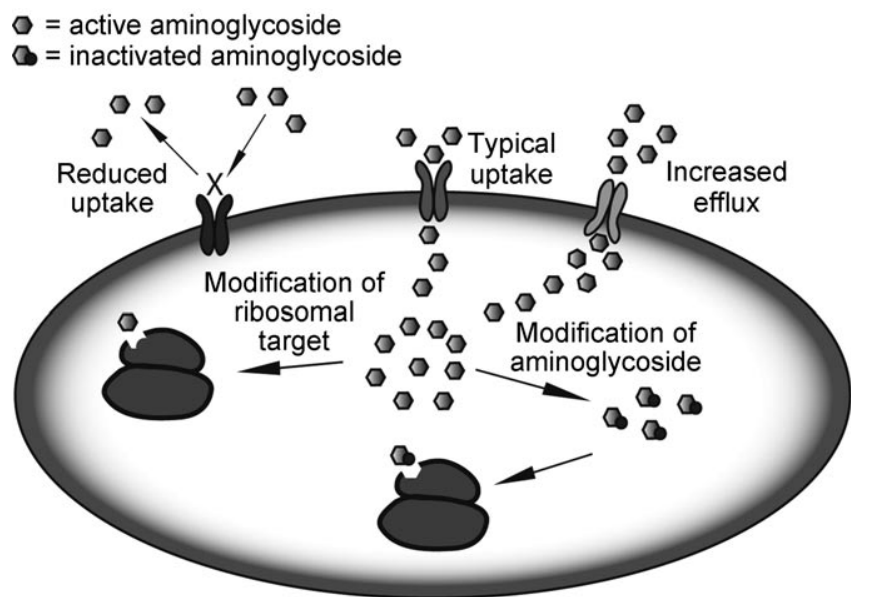

Figure 5. Depiction of the various mechanisms of bacterial resistance.

3.1.1. Reduced uptake and increased efflux: Although the exact mechanism of aminoglycoside uptake remains unclear, it is thought that three steps are involved. The first step is the adsorption of the polycationic aminoglycoside to the surface of bacteria by electrostatic interactions with the negatively charged portions of biomolecules found on the outer cell membranes of bacteria. ${ }^{[46-49]}$ In the case of Pseudomonas aeruginosa, changes in membrane components involved in interactions with aminoglycosides are associated with increased levels of resistance. ${ }^{[47,48]}$ The two subsequent steps are oxygen dependent, and this makes anaerobic bacteria intrinsically resistant to aminoglycosides. ${ }^{[50]}$ It was also found that in E. coli, Staphylococcus aureus, and P. aeruginosa, mutations in ATP synthases cause decreased susceptibility to aminoglycosides. ${ }^{[1]}$

In $P$. aeruginosa, efflux is a significant determinant of aminoglycoside resistance. ${ }^{[52]}$ Multidrug efflux pumps are energydependent active pumps that have recently been recognized as major contributors to some types of antibiotic resistance. ${ }^{[49,53-56]}$ Bacteria constitutively expressing such ATP-dependent transporters are intrinsically resistant to low levels of the antibiotics. Overexpression of these pumps is the result of mutations in the regulatory genes or increased concentration of drug substrates. One example of this efflux system is the resistance nodulation cell division (RND)-type transporter superfamily, ${ }^{[57,58]}$ which plays an important role in Gram-negative bacteria like $P$. aeruginosa. They typically operate as part of a tripartite system including a periplasmic membrane fusion protein (MFP) and an outer membrane factor, by using the membrane proton-motive force as an energy source. Another example is the major facilitator superfamily (MFS) of transporters. ${ }^{[59]} \mathrm{MdfA}$ from $E$. coli was the first discovered putative MFS protein that contributes to aminoglycoside resistance. In both cases, reduced accumulation of the aminoglycoside in the bacterial cell leads to decreased effectiveness of the compounds.

3.1.2. Modification of the target RNA: Another resistance mechanism that bacterial cells use is alteration of the aminoglyocisdes' target, the 16S RNA of the bacterial ribosome. Many aminoglycoside-producing organisms, including Streptomyces spp. and Micromonospora spp., are capable of expressing rRNA methylases, which are able to methylate the $16 \mathrm{~S}$ rRNA. ${ }^{[60,61]}$ One example, RmtA, was identified as a 16S rRNA methylase capable of conferring high-level aminoglycoside resistance in $P$. aeruginos $a_{1}^{[62]}$ whereas another example, $R m t B$, was found to be responsible for aminoglycoside resistance in Serratia marcescens. ${ }^{[60]}$ Recently, another putative $16 \mathrm{~S}$ rRNA methylase, ArmA, conferring high-level resistance to aminoglycosides, was found in a Klebsiella pneumoniae clinical isolate. ${ }^{[63]}$ Resistance to aminoglycosides resulting from a mutation of the ribosomal target has also been found in clinical isolates of Mycobacterium tuberculosis. ${ }^{[64]}$ In general, the modifications carried out by these enzymes occur in two highly conserved regions and result in decreased affinity of the aminoglycoside for its oligonucleotide partner such that the compounds are no longer effective. Westhof, Böttger, and co-workers are among those vying to alleviate these problems and to understand them at a molecular level. They suggest that perhaps the greatest tool researchers have to understand and, in time, overcome these types of phenomenon is crystallographic data coordinated with binding data. Relatively speaking, this data on the ribosome has become available only recently but should aid in identifying the important interactions between RNA and aminoglycosides and eventually novel antibiotics. ${ }^{[7]}$

3.1.3. Modification of the aminoglycoside: Even though the target site for aminoglycosides is often the 16S rRNA, the most common cause of aminoglycoside resistance is not conferred by alteration of this target, owing to the highly preserved function of the rRNA across genera. Rather, the most common mechanism for bacterial resistance arises from the structural modification of the aminoglycosides by specific enzymes expressed by resistant strains. The aminoglycoside-resistance genes are derived from bacterial genes that once encoded for enzymes involved in normal cellular metabolism. Over time, the selective pressure of aminoglycoside use altered the expression patterns of these genes, ultimately leading to the production of enzymes that are capable of regiospecifically modifying aminoglycosides, effectively rendering them inert. Most modifications take place at the 1-, 3-, 2'-, and 6'-amino groups and the $3^{\prime}-$, 4'-, and 2'-hydroxyl groups (Figure 6, kanamycin B 


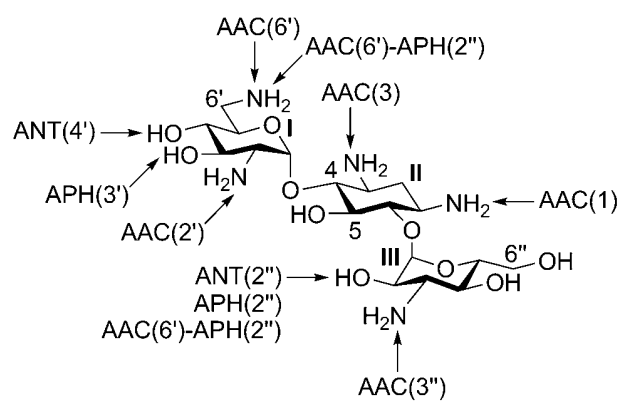

Figure 6. Aminoglycoside-modifying enzymes' modification sites on kanamycin B.

shown). ${ }^{[65]}$ Aminoglycosides with alternate structures can have variable amounts of modifiable sites, with the majority of these positions being located on rings I and II.

There are three classes of aminoglycoside-modifying enzymes (AMEs): ATP-dependent aminoglycoside nucleotidyltransferases (ANTs), ATP (and/or GTP)-dependent aminoglycoside phosphotransferases (APHs), and acetyl-CoA-dependent aminoglycoside acetyltransferases (AACs) (Scheme 1). Within each class, enzymes are grouped according to their different

nosa. ${ }^{[70,71]}$ The various sites of modification demonstrated with kanamycin B are shown in Figure 6.

Although these enzymes are often found in harmful bacteria, one useful application of AMEs is as resistance markers in molecular biology research. For example, the $\mathrm{Kan}^{\mathrm{R}}$ gene, which codes for an $\mathrm{APH}\left(3^{\prime}\right)$, leads to the phosphorylation of kanamycin $A$ at the $3^{\prime}$-position. As a result, cells carrying this gene are able to survive treatment with kanamycin $A .{ }^{[73,74]}$

It has become apparent that the future of rational antimicrobial drug design will rely heavily on our understanding of the targets involved, as well as the rapidly evolving biological mechanisms of resistance. In the case of aminoglycosides, understanding the modifying enzymes at a structural level is a goal of many researchers in the field because it will allow us to investigate at the structural level the interactions of various aminoglycosides with their targets and resistance enzymes.

3.1.3a. Aminoglycoside acetyltransferases (AACs): Over 50 members of the AAC family have been identified. These enzymes catalyze the acetyl-CoA-dependent $\mathrm{N}$-acetylation of aminoglycosides. They modify the 1- and 3-amino groups of the central 2-DOS ring (ring II, Figure 6) and the 2 '- and 6 '-amino groups of the 6-deoxy-6-aminoglucose ring (ring l, Figure 6). Two AAC(1) enzymes have been found in E. coli and actinomycetes strains, but their clinical importance is minor due to the fact that neither have been reported in dangerous pathogenic bacterial strains. ${ }^{[75,76]}$

The AACs that acylate at the 2 '-amino group are all chromosomally encoded and $A A C\left(2^{\prime}\right)$-la was the first to be identified from Providencia stuartii in 2001. ${ }^{[77,78]}$ Interestingly, mutations in the $\operatorname{aac}\left(2^{\prime}\right)$-la gene might cause increased levels of peptidoglycan O-acetylation, suggesting that peptidoglycan acetylation might be the original physiological function of the enzyme. The chromosomally en-

regiospecificities for aminoglycoside modifications. There are four nucleotidyltransferases (ANT(6), ANT(4'), ANT( $\left.3^{\prime \prime}\right)$, and ANT $\left.\left(2^{\prime \prime}\right)\right)$, seven phosphotransferases $\left(\operatorname{APH}\left(3^{\prime}\right), \operatorname{APH}\left(2^{\prime \prime}\right)\right.$, $\operatorname{APH}\left(3^{\prime \prime}\right), \operatorname{APH}(6), \operatorname{APH}(9), \operatorname{APH}(4)$, and $\left.\operatorname{APH}\left(7^{\prime \prime}\right)\right)$, and four acetyltransferases $\left(\mathrm{AAC}\left(2^{\prime}\right), \mathrm{AAC}(3)\right.$ (including $\left.\mathrm{AAC}\left(3^{\prime \prime}\right)\right), \mathrm{AAC}\left(6^{\prime}\right)$, $A A C(1))$. The enhanced intracellular survival (Eis) protein, an AAC that confers resistance in $M$. tuberculosis, has also recently been reported. ${ }^{[66]}$ There is also a bifunctional enzyme $A A C\left(6^{\prime}\right)$ $\operatorname{APH}\left(2^{\prime \prime}\right)^{[65,67,68]}$ that can catalyze both acetylation and phosphorylation of its substrates. Recently, three additional genes encoding bifunctional enzymes, designated ANT( $\left.3^{\prime \prime}\right)$-li/AAC $\left(6^{\prime}\right)$ -

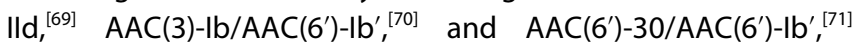
have been isolated from S. marcescens ${ }^{[69,72]}$ and P. aerugi- coded M. tuberculosis AAC (2')-Ic was shown, in contrast to some other AACs, to be active against amikacin and kanamy$\operatorname{cin} A$, both of which contain a 2'-hydroxyl group; this suggests that this enzyme can also catalyze O-acetylation. ${ }^{[79]}$ The structures of the apo form of AAC (2')-lc with CoA and tobramycin, kanamycin $A$, or ribostamycin are reported (Figure $7 \mathrm{~A}$ ). ${ }^{[80-82]}$

The 6 -amino group plays an important role in rRNA binding as probed by the structural analysis of bound aminoglycosides to the $30 \mathrm{~S}$ ribosomal subunit. ${ }^{[83,84]}$ Thus, the $6^{\prime}$-position is, not surprisingly, the target of one of the major classes of aminoglycoside-modifying enzymes, the $A A C\left(6^{\prime}\right)$ sub-family, which consists of more than 25 members. Type-I AAC $\left(6^{\prime}\right)$ causes resistance to the majority of useful aminoglycosides. Three enzymes have been extensively studied, including two chromosomally 

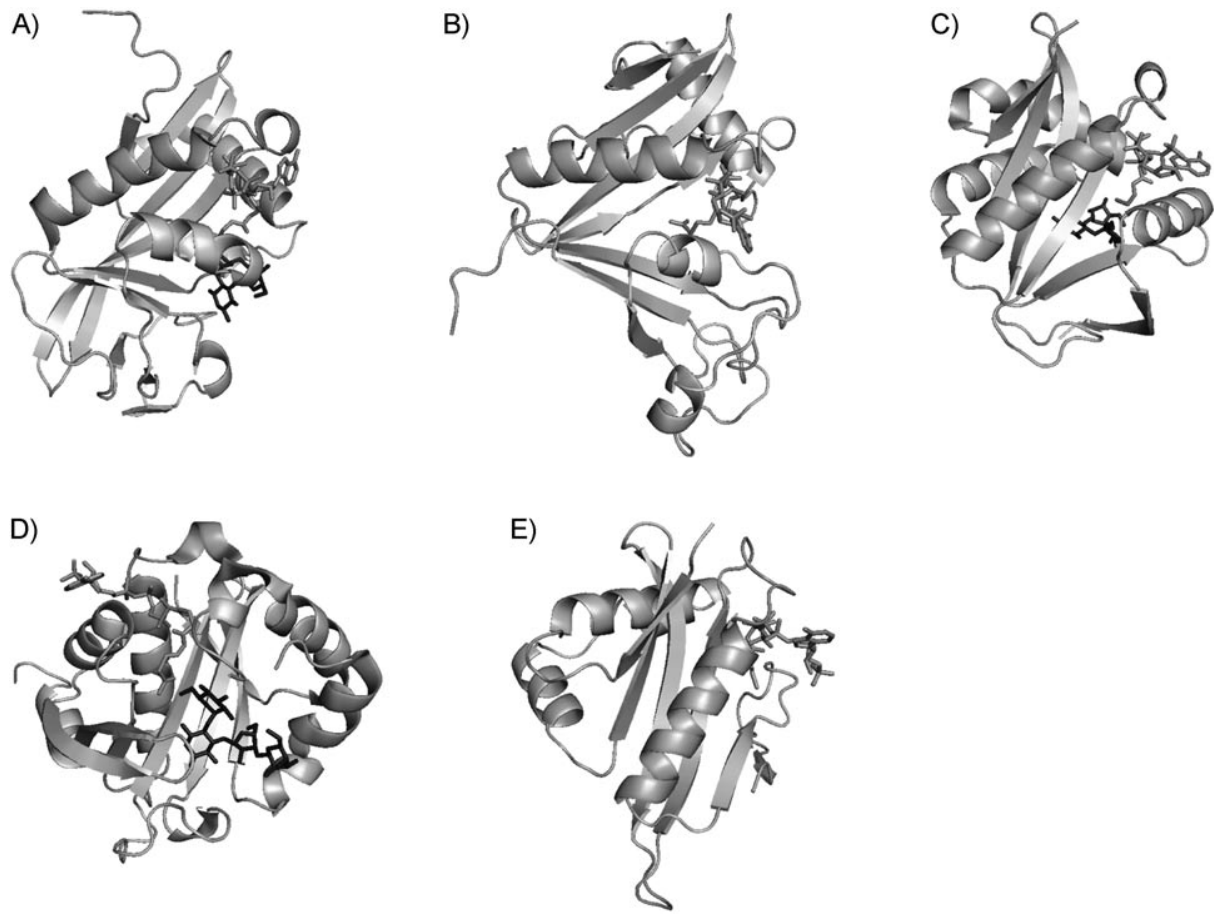

Figure 7. Crystal structures of various $A A C s$. A) $A A C\left(2^{\prime}\right)-I C$ (PDB ID: 1M4G) in complex with CoA and ribostamycin, B) AAC (6')-li (PDB ID: 1B87) in complex with acetyl-CoA, C) AAC(6')-ly (PDB ID: 1S3Z) in complex with CoA and ribostamycin, D) AAC(6')-lb (PDB ID: 2VQY) in complex with acetyl-CoA and paromomycin, E) AAC(3)-la (PDB ID: 1BO4) in complex with CoA. CoAs and aminoglycosides are shown. The overall structural folds place those AACs in the GCN5 acetyltransferase superfamily. There are four key structural modules per structure.

Although the primary amino acid sequence identity among these AAC enzymes is negligible, the overall structural fold places AACs in the GCN5-related N-acetyltransferase (GNAT) superfamily. Structural and mechanistic studies have aided our understanding of the interactions between the enzyme and the aminoglycoside, and in the future will aid in the design of new drugs that avoid deactivation by AACs.

3.1.3b. Aminoglycoside phosphotransferases (APHs): Aminoglycoside phosphotransferases catalyze the regiospecific transfer of the $\gamma$-phosphoryl group of ATP (or other nucleotides) to a hydroxyl group on an aminoglycoside (Scheme 1 and Figure 6). The genes encoding these enzymes are often found on multidrug-resistance $\mathrm{R}$ plasmids, transposons, and integrons, and thus are hurdles in the treatment of some enterococcal and staphylococcal species with aminoglycosides. Phosphorylation of ami-

encoded $A A C\left(6^{\prime}\right)-\mathrm{li}^{\prime} \mathrm{s}^{[81]}$ from Enterococcus faecium (Figure 7B), $A A C\left(6^{\prime}\right)-1 y^{[85-87]}$ from Salmonella enterica (Figure $7 C$ ), and a plasmid-encoded bifunctional enzyme $A A C\left(6^{\prime}\right)$-le/APH(2")-la found in enterococci and staphylococci. ${ }^{[88]}$ Two of the other $\operatorname{AAC}\left(6^{\prime}\right)$ members, $A A C\left(6^{\prime}\right)$-li and $A A C\left(6^{\prime}\right)-l b$ (Figure $\left.7 D\right)$, have also been well studied. ${ }^{[89-93]}$

A recently discovered variant of $A A C\left(6^{\prime}\right)$, the $A A C\left(6^{\prime}\right)-\mathrm{lb}-\mathrm{cr}$, has been shown to be able to modify aminoglycosides as well as fluoroquinolones. ${ }^{[94]}$ It seems likely that the steady increase in the clinical use of ciprofloxacin during the 1990s has generated selective pressure for this variant. ${ }^{[95]}$

The bifunctional enzyme AAC $\left(6^{\prime}\right)-\mathrm{le} / \mathrm{APH}\left(2^{\prime \prime}\right)-\mathrm{la}$, which confers broad spectrum aminoglycoside resistance differs from the other $A A C\left(6^{\prime}\right) s$ in its genetic location and catalytic capabilities. ${ }^{[88]}$ This enzyme has been proposed to arise by gene fusion and to confer a wider range of aminoglycoside resistance, illustrating the ability of bacteria to adapt to changes in aminoglycoside use and selective pressure. ${ }^{[96,97]}$

The AAC(3) subfamily is one of the largest AME family of enzymes and includes four major types, I-IV, based on the aminoglycoside-resistance profile. The AAC(3)-I from S.marcescens was the first AAC whose $3 D$ structure was determined (Figure 7E). ${ }^{[82,98]}$ The enzyme-CoA complex determined at $2.3 \AA$ allowed for identification of the interactions between the enzyme and the product. Unfortunately, there is no structure of $A A C(3)$ with bound aminoglycoside substrate available at this time. noglycosides results in a dramatic decrease in their ability to bind to their target on the A-site of the ribosome.

The largest and most well-studied sub-families of APHs are the $\mathrm{APH}\left(3^{\prime}\right) \mathrm{s}$, and the best-studied enzyme of this class is the plasmid-encoded $\mathrm{APH}\left(3^{\prime}\right)$-IIla from Enterococcus faecalis. ${ }^{[99,100]}$ Interestingly, tobramycin, which lacks the 3 '-hydroxyl group, is not a substrate but rather a potent inhibitor of $\mathrm{APH}\left(3^{\prime}\right)-\mathrm{IIla} .^{[100]}$ It was also found that for aminoglycosides lacking a $3^{\prime}$-hydroxyl group, such as lividomycin A, phosphorylation can occur at the $5^{\prime \prime}$-hydroxyl group of the ribose ring. ${ }^{[101]}$ In the case of butirosin and neomycin B, both of which have 3'- and 5"-hydroxyl groups, phosphorylation was found to occur at either position. Those 4,5-disubstituted aminoglycosides were shown to be rapidly monophosphorylated, and subsequently diphosphorylated. ${ }^{[101,102]}$

The crystal structure of the APH(3')-Illa-ADP complex was solved in 1997 (Figure 8A, B). ${ }^{[102]}$ Despite a complete lack of sequence homology to eukaryotic protein kinases, $\mathrm{APH}\left(3^{\prime}\right)$-IIla displays a striking similarity to several kinases, with nearly half of the $\mathrm{APH}\left(3^{\prime}\right)$-IIla sequence adopting a conformation identical to that seen in eukaryotic kinases. Recently, Fong and Berghuis demonstrated that further derivatization of the AHB group is a promising strategy for producing aminoglycosides with the potential to elude inactivation by $\mathrm{APH}$ enzymes. ${ }^{[103]}$ Another common APH found in a variety of Gram-negative bacteria (Avibacterium paragallinarum and E. coli) is $\mathrm{APH}\left(3^{\prime}\right)$-la, which 

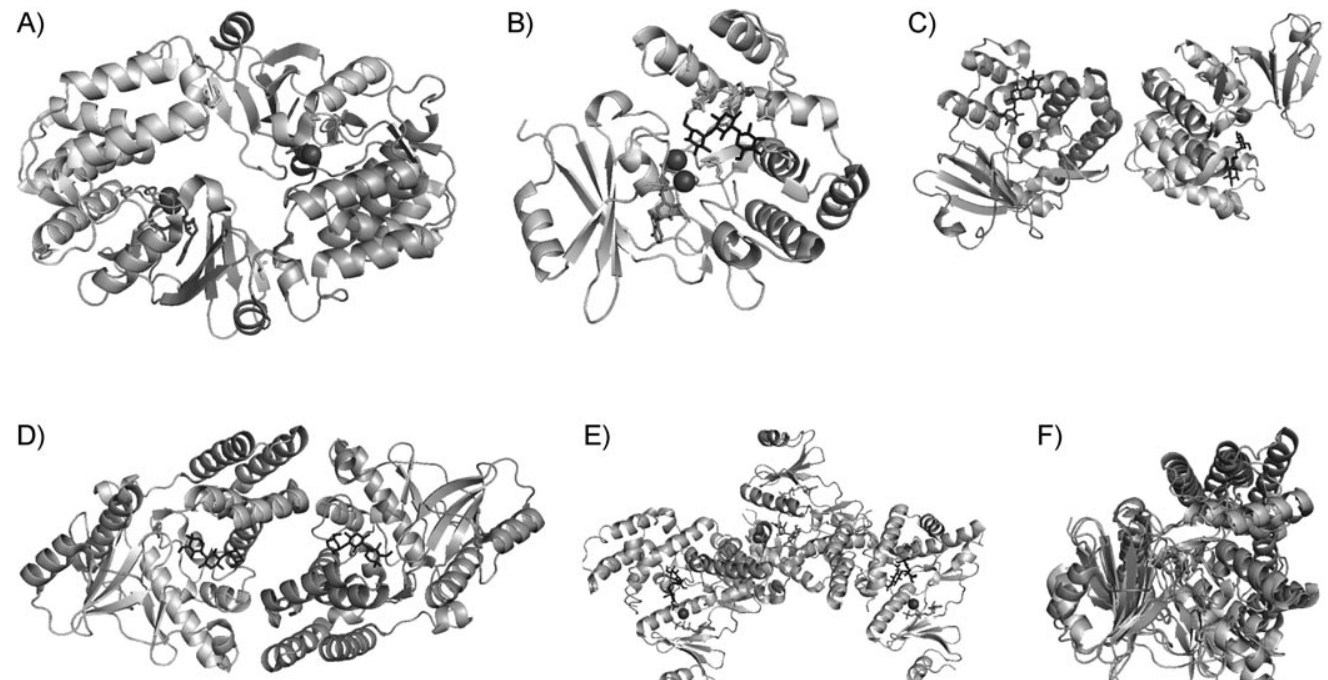

E)

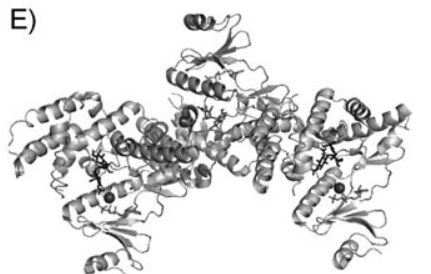

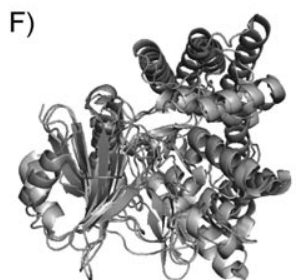

Figure 8. Crystal structures of various APHs. A) APH(3')-IIla (PDB ID: 1J7L) in complex with ADP. The enzyme exists as a doubly disulfide-bonded dimer. Each monomer consists of a C-terminal lobe and a smaller N-terminal lobe connected by a 12-residue linker region, B) APH(3')-Illa (PDB ID: 1L8T) in complex with ADP and kanamycin A. The C-terminal residues that make contacts with the aminoglycoside are highlighted in pale gray, C) APH(3')-Ila (PDB ID: 1 ND4) in complex with kanamycin A. The two monomers are displayed, D) APH(2")-Ila (PDB ID: 3HAM) in complex with kanamycin A. The two monomers are displayed, E) APH(3')-lla (PDB ID: 1ND4) in complex with streptomycin and ATP. Three monomers are shown, F) Superimposition of APH(3')-IIla (PDB ID: 1L8T), APH(3')-Ila (PDB ID: 1ND4), and APH(2")-lla (PDB ID: 3HAM). ATP/ADP and aminoglycosides are displayed as sticks. The spheres represent Mg ${ }^{2+}$ ions.

displays additional ATPase activity in the absence of an aminoglycoside. ${ }^{[104-106]}$ The X-ray crystal structure of $\mathrm{APH}\left(3^{\prime}\right)$-Ila in complex with kanamycin A became available in 2002 (Figure $8 \mathrm{C}) \cdot{ }^{[107]}$

Another member of this family for which there is structural information is $\mathrm{APH}\left(2^{\prime \prime}\right)$-Ila (Figure $8 \mathrm{D}$ ). ${ }^{[108]}$ The structures of two complexes, the binary gentamicin complex as well as a ternary complex containing ATP (adenosine triphosphate) and streptomycin, were reported (Figure $8 \mathrm{E}) .{ }^{[108]}$ Analysis of the two complexes gives insights as to why APH(2")-lla favors 4,6-disubstituted aminoglycosides as substrates rather than the 4,5-disubstituted antibiotics. In gentamicin, the molecule is easily able to adopt an extended conformation with a large spacing between the primed and doubly primed rings, whereas in streptomycin, such motion is constrained to adopt a sterically unfavorable conformation.

3.1.3c. Aminoglycoside nucleotidyltransferases (ANTs): Although they are the smallest family of aminoglycoside-modifying enzymes, aminoglycoside nucleotidyltransferases, with only ten enzymes identified to date, have a major impact on clinical resistance because both gentamicin and tobramycin are substrates of ANT $\left(2^{\prime \prime}\right)$. The genes encoding ANTs are widely found in pathogenic bacteria. The ant( $\left.4^{\prime}\right)$, ant(6), and ant(9) genes are found on plasmids or transposons in Gram-positive bacteria whereas the $\operatorname{ant}\left(2^{\prime \prime}\right)$ and $\operatorname{ant}\left(3^{\prime \prime}\right)$ are often found on mobile genetic elements in Gram-negative strains. These enzymes are able to catalyze an O-adenylation reaction between ATP and aminoglycoside in the presence of $\mathrm{Mg}^{2+}$ ions.

Enzymes that are able to regioselectively adenylate the 6and 3 "-positions of streptomycin and the 9- and 3"-positions of spectinomycin have been identified. The reactions catalyzed by ANT( $\left.2^{\prime \prime}\right)$ and ANT( $\left.4^{\prime}\right)$ are most significant and have been the most studied mechanistically. The enzyme exhibits activity with a broad array of 4,6-disubstituted substrates. ${ }^{[109]}$

Structural data for only one ANT has been reported, which is an ANT(4') from S. aureus. ${ }^{[110]}$ The crystal structure was reported as enzyme complexed with both the nonhydrolyzable nucleotide analogue AMPPCP and kanamycin (Figure 9). The AMPPCP molecule is locked into position by extensive hydrogen bonding, but there were few interactions found between the adenine ring and protein, which explains why ANT(4') accepts other nucleotides such as GTP. More recently, Mobashery and co-workers investigated the bifunctional ANT(3")-li/AAC(6')-Ild from S. marcescens. ${ }^{[69]}$ The structure assignment of the enzymatic products indicated that acetylation takes place on the 6 -amine of kanamycin $\mathrm{A}$ and the adenylation on the $3^{\prime \prime}-$ and

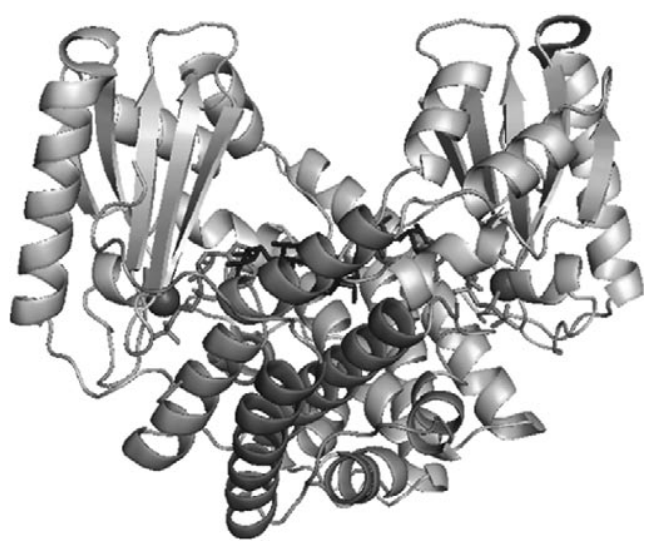

Figure 9. Crystal structure of ANT(4') (PDB ID: 1 KNY) in complex with AMPPCP and kanamycin A. The enzyme functions as a dimer and each monomer is divided into two structural domains ( $\mathrm{N}$-terminal and $\mathrm{C}$-terminal domains) of approximately equal size. The spheres represent $\mathrm{Mg}^{2+}$ ions. 
9-hydroxyl groups of streptomycin and spectinomycin, respectively.

\subsection{Toxicity}

One of the primary obstacles preventing the more widespread use of aminoglycosides as a long-term treatment for genetic, viral, or microbial issues is the inherent toxicity associated with nonspecific binding of RNA. The toxicity of aminoglycosides has been realized in mammals for decades, and understanding the mechanisms of toxicity has been the goal of many research efforts. Some of the most important risk factors for aminoglycoside-induced toxicity include: the duration, dosage, and frequency of therapy, the patient's age, the patient's liver and kidney health, and drug-drug interactions with other potential nephrotoxic agents. ${ }^{[111,112]}$

Toxicity and selectivity are two intertwining issues associated with targeting the ribosome due to its presence and importance in all forms of life. Böttger and Westhof were among the pioneers who laid the foundations for understanding how aminoglycosides, as well as other classes of antibiotics, interact with their ribosomal targets. Böttger and co-workers used biochemical techniques that allowed for the first steps to be taken towards rationalizing and making the connection between the various toxicities of aminoglycosides with their key structural elements. ${ }^{[7,18,113-116]}$ They showed that a single modification of a nucleotide or amino acid could, and in many cases does, determine the selectivity, and therefore toxicity, of drugs targeting the ribosome such as aminoglycosides. ${ }^{[117]}$ Thanks in large part to these contributions from geneticists and biochemists, correlations have been drawn between certain structural and biophysical properties of aminoglycosides as well as the ribosome itself. Baasov and co-workers have noted that, in general, aminoglycosides with fewer amino groups on the scaffold will show less toxicity, and the same is true of aminoglycosides with lower relative basicity of their existing amino groups, notably the $2^{\prime}$-amine. ${ }^{[118,119]}$ In this review, the two primary toxicities associated with aminoglycoside treatment, ototoxicity and renal toxicity, are discussed.

3.2.1. Nephrotoxicity: Nephrotoxicty, arising from toxins or drug compounds damaging the kidneys, is one of the most common problems that plague drug development. Kidney damage can lead to the body's inability to rid itself of urine and other wastes. If untreated, an eventual concurrent rise in electrolytes in the blood can lead to permanent kidney damage or, worse, kidney failure.

Aminoglycosides are primarily eliminated by glomerular filtration and excretion in the urine and, as a result, accumulation in the kidneys is observed. A significant accumulation of an aminoglycoside in the renal cortex tissue is an important determinant of aminoglycoside-induced nephrotoxicity. After reaching renal cortical tissue, aminoglycosides are absorbed through pinocytosis, and once absorbed show a high affinity for phospholipid membranes due to their polycationic nature. Once transferred to the lysosome, the strong binding of aminoglycosides to the negatively charged phospholipids results in a decrease of lysosomal phospholipase activity. An abnormal increase in size and number of lysosomes were found with decreased lysosome stability. ${ }^{[120]}$ Although hydration treatment can often alleviate the symptoms of aminoglycoside-induced nephrotoxicity, it is not always fully reversible and recovery can take many months.

3.2.2. Ototoxicity: Another major hurdle in aminoglycoside therapy is ototoxicity, which, in contrast to nephrotoxicity, is mostly irreversible. There are two types of ototoxicity: vestibular toxicity and cochlear toxicity. Aminoglycosides toxicity can lead to a temporary vestibular hypofunction or permanent high-frequency hearing loss. ${ }^{[121]}$ The permanence of aminoglycosides ototoxicity is a result of degeneration of hair cells and neurons in the cochlea, which do not regenerate once damaged.

Whereas aminoglycosides can degenerate cochlear and vestibular cells by binding to phospholipids and by disrupting mitochondrial protein synthesis, ${ }^{[120,122]}$ it is thought that aminoglycoside molecules are not always ototoxic themselves, but, rather, they require interaction with a transition-metal ion. Chelation of metal ions from biomolecules and/or endogenous coordination sites can produce redox-active complexes capable of generating reactive oxygen species (ROS), which are in turn capable of causing oxidative damage that leads to ototoxicity. There are also genetic factors that have been identified that increase a person's susceptibility to certain types of ototoxicity. ${ }^{[123]}$ Other possible mechanisms of ototoxicity include increased activity of cochlear $\mathrm{N}$-methyl-D-aspartate receptors ${ }^{[124]}$ and/or nitric oxide synthase. ${ }^{[125]}$

A genetic analysis of aminoglycosides interactions with eukaryotic rRNA has led Böttger and co-workers to propose that aminoglycosides interfere with mitochondrial protein synthesis and that this increases the cochlear toxicity associated with aminoglycosides. ${ }^{[126]}$ This pathogenic mechanism seems to rely on mitochondrial mutations that cause a genetic predisposition to aminoglycoside hypersensitivity. This hypothesis is strongly supported by crystallographic analysis of RNA duplexes of human wild-type decoding A-sites, the human A1555G mutant (which is associated with nonsyndromic hearing loss), and bacterial decoding A-sites. ${ }^{[127]}$ Thus, it stands to reason that there are a number of contributing factors associated with both the genetic and dose-dependent aminoglycoside-induced hearing loss. For a thorough review on aminoglycoside-induced ototoxicity see Guthrie. ${ }^{[121]}$

3.2.3. Alleviating aminoglycoside-associated toxicity: Currently, a general strategy for decreasing the toxicity of aminoglycosides due to nonspecific binding is the development of novel derivatives that are specific for their target RNA sequences, whether bacterial, viral, or human. Modifying the aminoglycoside scaffold by the addition, removal, or replacement of some functionality might prove a successful strategy in producing compounds with lower levels of nephrotoxicity (Sections 4 and 5).

One example is the $\mathrm{N} 1$ modification of known aminoglycosides (Section 2.1); these analogues have shown decreased nephrotoxicity. The nonionizable $\mathrm{N} 1$ acyl position reduces the 
binding affinity of the compounds for negatively charged phospholipids and, thus, reduces accumulation in the kidneys. ${ }^{[128]}$ Whether this strategy will lead to more efficacious treatments with significantly lower toxicity remains to be seen, but currently the future is undoubtedly promising. For an indepth review of nephrotoxicity, see Mingeot-Leclercq et al. ${ }^{[129]}$

A recent strategy aimed at alleviating the ototoxicity is the development of otoprotective therapies that prevent or alleviate aminoglycoside ototoxicity. One such strategy for ameliorating the ototoxicity caused by gentamicin is the induction of heat shock protein 70 (Hsp70) by geldanamycin. Mazurek and co-workers showed that geldanamycin is able to induce Hsp70 in auditory sensory cells and partially protect them from gentamicin toxicity. ${ }^{[130]}$ This is an exciting advance because this type of research could lead to preventative therapy for hearing loss associated with the use of aminoglycosides, and further improve the possibility of aminoglycosides enjoying more widespread application in the future.

\subsection{Problems associated with aminoglycosides' total syntheses}

Although chemical synthesis is a great tool for generating large quantities of aminoglycosides, producing a large library of compounds is often an overwhelming task. This fact was evidenced in the early work on aminoglycosides reported by
Hannesian and co-workers on a number of modified aminoglycosides and is still evident today. ${ }^{[131-134]}$ The steps required to manipulate saccharide rings into the correct protection states quickly grow quite numerous, often providing only enough material to test for MIC and toxicity from grams of starting material. Combinatorial methods (Section 4.1.2) have taken a step closer to generating a larger number of compounds by using a single reaction, however, the starting materials in these reactions still require the appropriate protection chemistry (Figure 10 and Scheme 2).

The overall yields of syntheses of complex molecules are often very low, and aminoglycosides are no exception. The synthesis of the starting material for the fluorous purification of a disaccharide (Scheme 2) resulted in a $42 \%$ yield of 22 (Ac) or a $21 \%$ yield of $\mathbf{2 1}$ (Fmoc). There were five more steps in this synthesis and over half of the starting material was quickly lost to poor yields. Also, as demonstrated by the neomycin B biomimetics (Section 4.1.1), generating complex aminoglycoside mimetics can also lead to low overall yields of ultimately inactive compounds, highlighting the pitfalls of spending valuable resources that could otherwise be focused elsewhere.

In addition to the multitude of reactions required to synthesize aminoglycosides, most of the syntheses start from the degradation of neomycin B to neamine, retaining rings I and II. Whereas these rings are the most important for the pseudostreptamine/ribosomal-binding aminoglycoside family, few

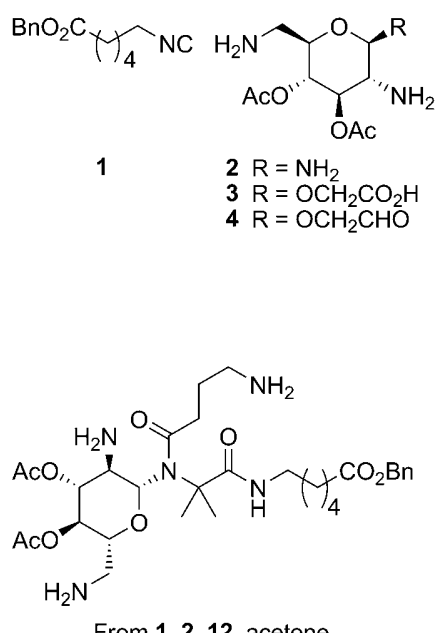

From 1, 2, 12, acetone

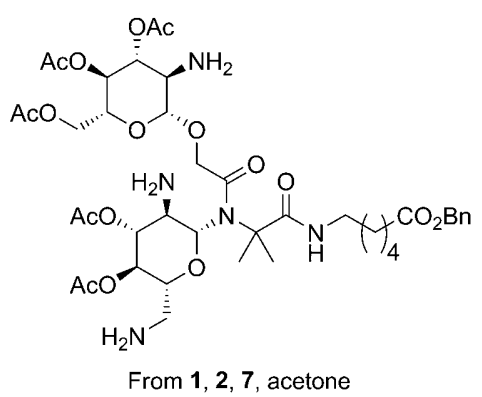

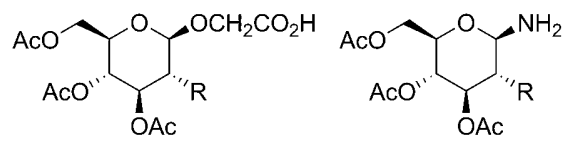

$5 \mathrm{R}=\mathrm{OAC}$ $6 \mathrm{R}=\mathrm{NHAC}$ $7 \mathrm{R}=\mathrm{NH}_{2}$<smiles>CC(=O)OC[C@H]1O[C@H](OCC(=O)N([C@H]2O[C@H](COC(C)=O)[C@@H](OC(C)=O)[C@H](OC(C)=O)[C@H]2OC(C)=O)C(C)(C)C(=O)NCC(C)(C)C(=O)OCc2ccccc2)[C@H](OC(C)=O)[C@@H](OC(C)=O)[C@@H]1OC(C)=O</smiles>

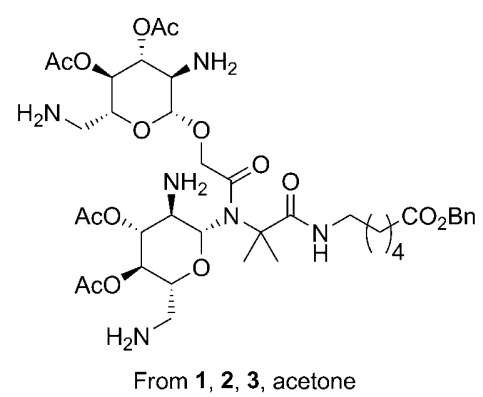<smiles>[R]O[C@@H]1[C@@H]([R])[C@@H](OC(C)=O)O[C@H](COC(C)=O)[C@@H]1OCC(=O)O</smiles>

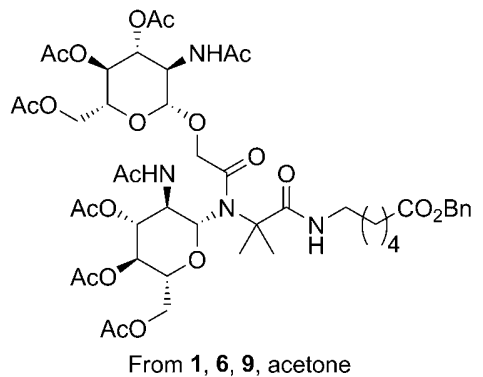<smiles>CC(=O)OC[C@H]1O[C@H](O)[C@@H](OC(C)=O)[C@H](OC(C)=O)[C@H]1OC(C)=O</smiles><smiles>CC(=O)OC[C@H]1O[C@H](OC[C@H](C(=O)NCC(C)(C)C(=O)OCc2ccccc2)N(C(=O)CCl)[C@H]2O[C@H](COC(C)=O)[C@@H](OC(C)=O)[C@H](OC(C)=O)[C@H]2OC(C)=O)[C@H](OC(C)=O)[C@@H](OC(C)=O)[C@@H]1OC(C)=O</smiles>

Figure 10. Generation of aminoglycoside-like compounds by using a multicomponent Ugi reaction. 


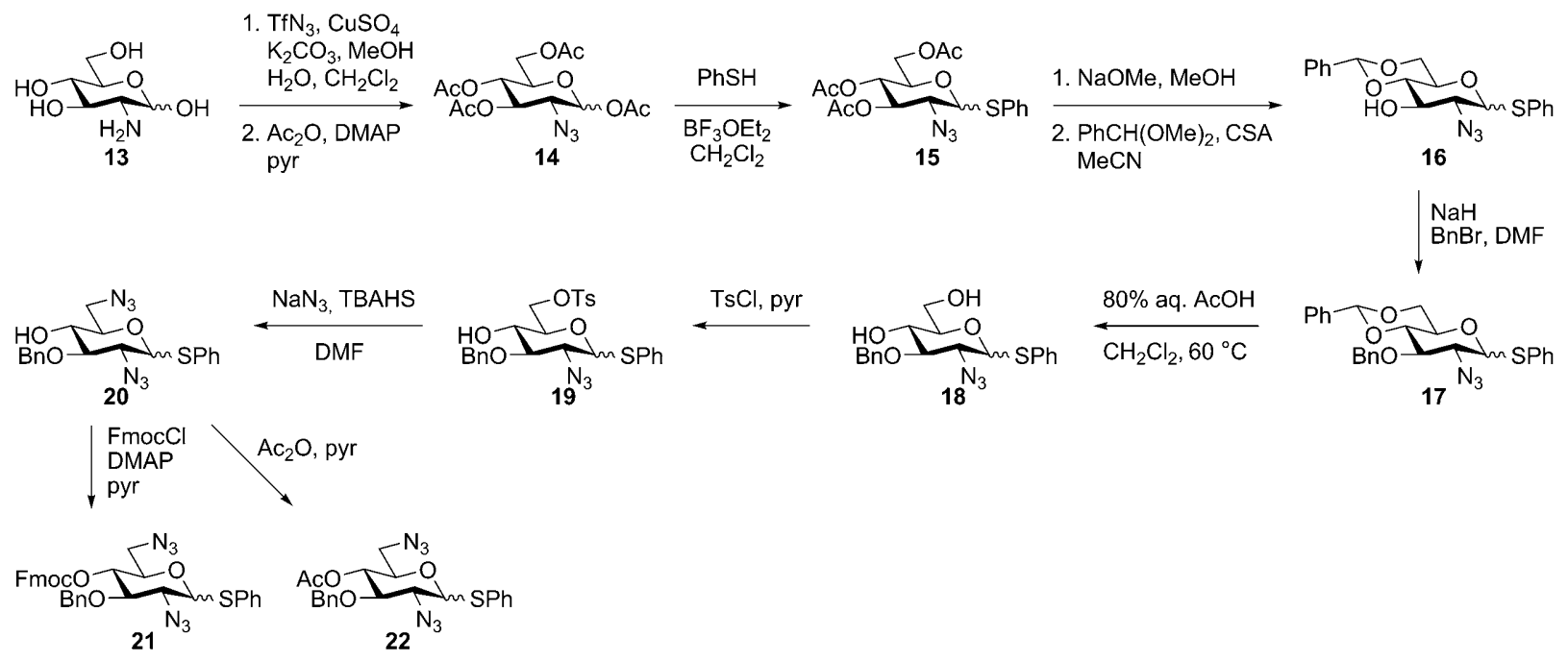

Scheme 2. Representative example of common protection and deprotection steps used to render the correct position open for reaction.

other conformations have been thoroughly investigated. It seems that many investigators are content to either modify the current aminoglycosides, a method that has proven useful in the production of amikacin, arbekacin, and butirosin, or start from the neamine core and derivatize rings I and II.

Chemoenzymatic methods hold great promise in generating large libraries of compounds. Although generating large amounts of material chemoenzymatically can be challenging, enough material can be produced to discover promising compounds to further pursue synthetically. There are also many other techniques currently being developed or already in practice that will allow for a simplified approach, which is less time consuming and more efficient than the classical synthetic methods for developing novel aminoglycosides.

\section{Synthetic Efforts towards Improved Aminoglycosides}

The inherent toxicity as well as the emergence of resistance to the most commonly used aminoglycosides has held in check their efficacy as front-line antibacterial treatments. Additionally, there exists an inherent difficulty in designing a molecule to specifically target a particular RNA while not binding to undesired cellular RNAs. Consequently, novel aminoglycoside-based compounds with improved target selectivity and reduced toxicity are the goal of many aminoglycoside-related drug discovery efforts. One promising strategy is the chemical modification of known aminoglycosides to include some additional functionalities that are capable of differentially binding the RNA target, resulting in greater binding affinity, reduced toxicity, and/or greater target selectivity. This section will discuss some of the promising types of modified aminoglycosides and the methods used to generate the compounds. The compounds discussed will be divided into three general classes based on the nature of the modified product.

\subsection{Novel aminoglycoside derivatives}

4.1.1. Traditional synthetic methods: The synthesis of carbohydrates in any form requires multiple protecting group manipulations. Early work performed by Hanessian and co-workers, among others, showed that modifying the scaffold of aminoglycosides could lead to improved activity in a number of cases. ${ }^{[132-134]}$ However, these syntheses were challenging regardless of how minor the alterations to the compounds might have seemed.

The synthesis of an appropriately protected carbohydrate, for instance compounds $\mathbf{2 1}$, and 22, that was used in the first step of a disaccharide synthesis by using fluorous tags to simplify the purification is shown in Scheme $2 .{ }^{[135]}$ This example is representative of the work required to make a disaccharide. To synthesize the appropriately protected aminoglycoside took ten steps, and five more steps remained to synthesize the disaccharide. Because most aminoglycoside antibiotics range from three to five rings, the total synthesis of antibiotics starting from base glycosides is a tedious task. Other examples of long protection and deprotection routes can be found in the literature. ${ }^{[136]}$

Some solutions to these problems have been found, and although most of these solutions are specific to a particular problem, the progress made has been substantial. One alternative to multistep protections and deprotections involves metal chelation directed reactions as used by Nudelman et al. ${ }^{[5]}$ In this example, zinc was used to preferentially protect the amino group at the 1-position. Afterwards they were able to preferentially react the N1-position with AHB. After several more steps the novel paromomycin derivative, NB54, was generated. NB54 was found to suppress PTCs better than gentamicin, paromomycin, and its nonAHB-containing counterpart NB30, while also proving less toxic than paromomycin and gentamicin. ${ }^{[45]}$

Alternatively, many reported syntheses of aminoglycoside derivatives begin with the protection and hydrolysis of neomycin to generate the neamine core of many aminoglycosides, leaving the 5-hydroxyl group of the 2-DOS ring open for deri- 
vatization (Scheme 3). ${ }^{[136-138]}$ The example depicted in Scheme 3 shows a series of compounds that were obtained by such a method. The series was tested for RNA binding and some derivatives were found to bind RNA in the sub-micromolar range.

A similar approach was used in 2003 when Fridman et al. synthesized a series of neomycin $B$ derivatives modified at the $5^{\prime \prime}$-hydroxyl position. ${ }^{[139]}$ A series of protected aminoglycoside monomers were reacted with an activated and protected neomycin B. The number of steps ranged from 7 to 15 steps, depending on the complexity of the monomer. Most of these derivatives gave greater MIC values than neomycin B for all bacteria tested.

Aminoglycosides, namely apramycin (38) and saccharocin (39), have also been synthesized by starting from neamine (30; Scheme 4). ${ }^{[140]}$ Compound 35 was obtained from neamine (30) and then, after several additional steps was reacted with protected fluorous glycoside 37 , to yield apramycin or saccharocin, another lengthy yet fruitful synthesis.

Neomycin B biomimetics from which either ring IV was removed, or ring III was replaced by an ethylene group have been synthesized. ${ }^{[111]}$ These compounds were obtained by first degrading neomycin B to neamine. The ring III mimic was synthesized and coupled to neamine by stirring in an acidic milieu to yield the biomimetics of rings I, II, and III in $0.04 \%$ overall yield. A mimetic of ring IV was generated and coupled to neamine in the same manor as above to give a $0.79 \%$ overall yield. These compounds were obtained in very low overall yield and did not display significant antiviral activity.
The previous examples are representative of the difficulties of chemically synthesizing novel aminoglycoside compounds. Although many of the intricate building blocks for the syntheses of novel monomeric aminoglycosides are accessible, the synthesis of innovative structures with improved or unique activity by chemical methods can be quite challenging.

4.1.2. Combinatorial methods: To side-step some of the problems with traditional linear or parallel synthesis of aminoglycosides and other carbohydrates, several combinatorial approaches have been devised. Figure 10 shows a small library of compounds that have been used in an Ugi multicomponent reaction. ${ }^{[142]}$ This method uses a one or two-step reaction to obtain the aminoglycosyl starting materials 2, 3, and 4. This work found that combining all components in $0.2 \mathrm{M}$ methanolic solution worked well for components pre-condensed with the amine and carbonyl-containing compounds. Eight aminoglycoside mimics were made from various combinations of carboxylic acid, aldehyde, nitrile, and amine.

In a similar manner, Wong and co-workers have also used a multicomponent reaction to generate neamine-amino acidglycol hybrids that were designed to target HIV RNA RRE (Scheme 5). ${ }^{[143]}$ Here they combined an amino-capped polyethylene glycol (PEG), aldehyde 40, isonitrile, and amino-protected amino acid in TFA and stirred for five days. After the reaction period the investigators isolated the compound $\mathbf{4 2}$, which contained neamine, one of thirteen amino acids, and $\mathrm{PEG}_{115}$ linker. These compounds were shown to inhibit the Rev/RRE binding at $200 \mu \mathrm{M}$.
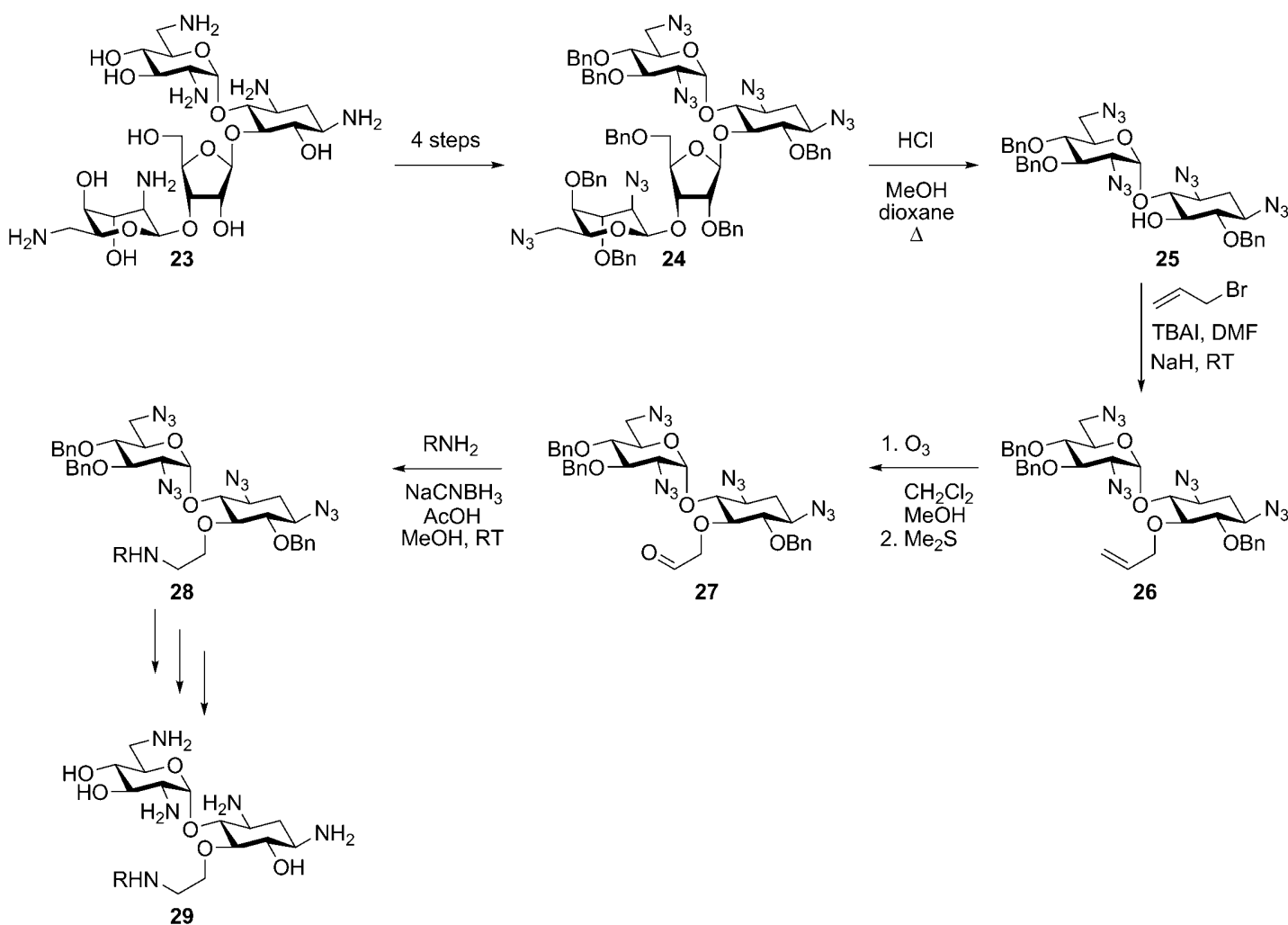
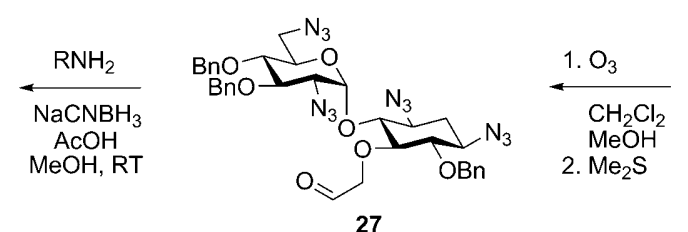

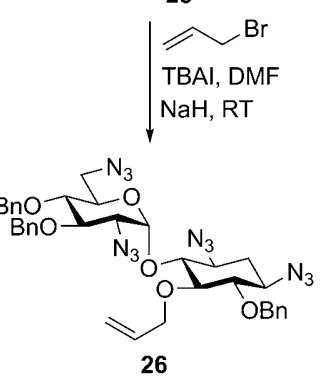

26

Scheme 3. Synthesis of 5-hydroxyl neamine derivatives. 


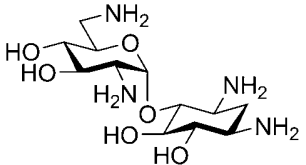

30
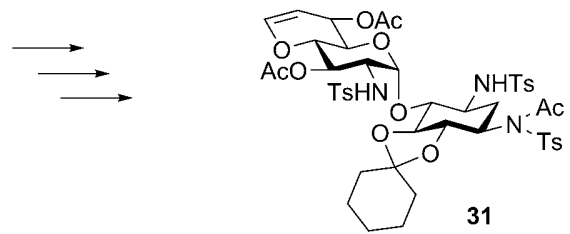

$\underset{\mathrm{MeCN}}{\stackrel{\mathrm{NaN}_{3}, \mathrm{CAN}}{\longrightarrow}}$

31
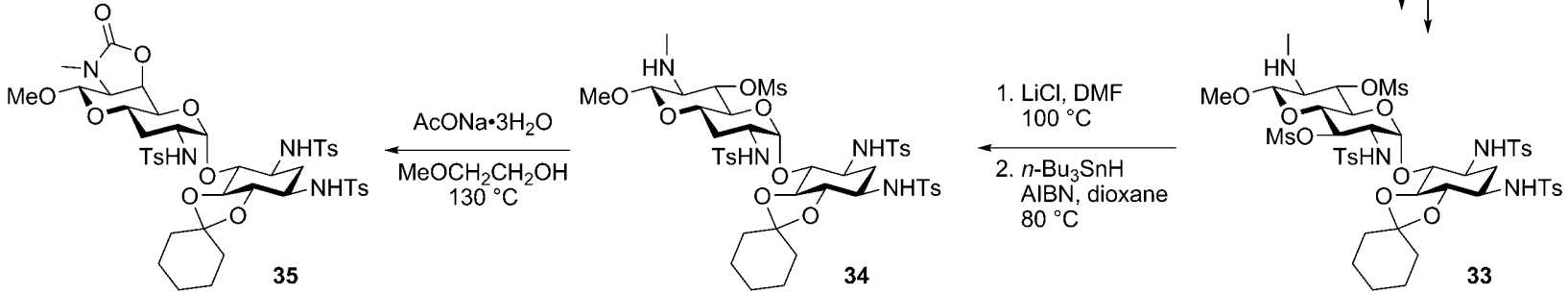
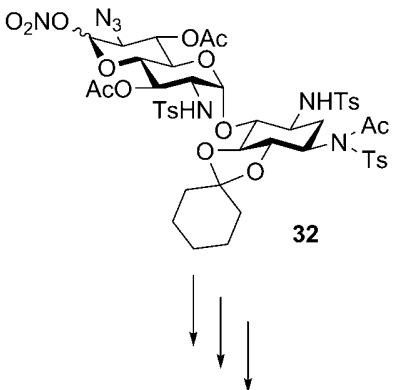
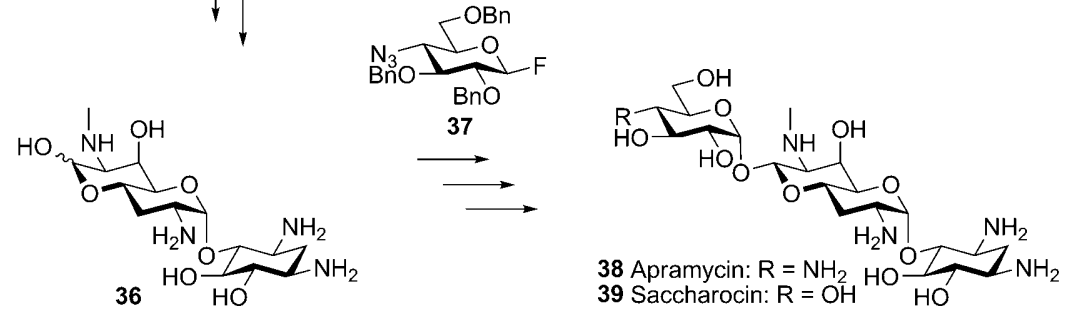

Scheme 4. Highlighted steps in the synthesis of apramycin and saccharocin.

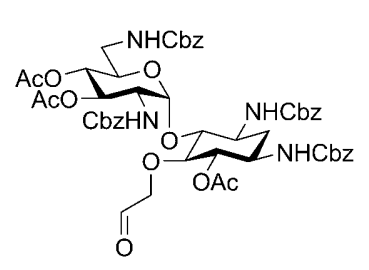

40

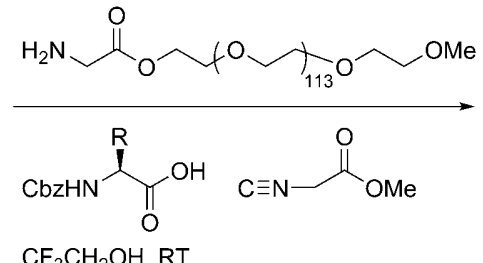

$\mathrm{CF}_{3} \mathrm{CH}_{2} \mathrm{OH}, \mathrm{RT}$
Scheme 5. Synthesis of neamine, polyethyleneglycol, and amino acid trimers.

\subsection{Aminoglycoside dimers}

Aminoglycoside homo- and heterodimers have shown promise towards a variety of targets (Section 5.1). ${ }^{[144]}$ Dimers are generally produced by using semisynthetic methods, by starting

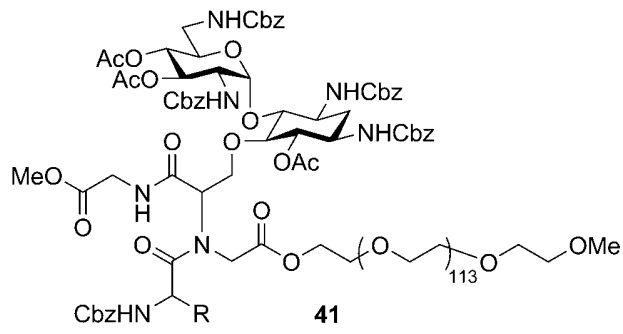

$\mathrm{R}=$ side chains of Gly, Ala, Val, Phe, Trp, His, Tyr, Thr, Ser, Asp, GIn, Lys, and Arg

1. $\mathrm{LiOH}, \mathrm{H}_{2} \mathrm{O}, \mathrm{MeOH}$ 2. $10 \% \mathrm{Pd} / \mathrm{C}, \mathrm{AcOH}$

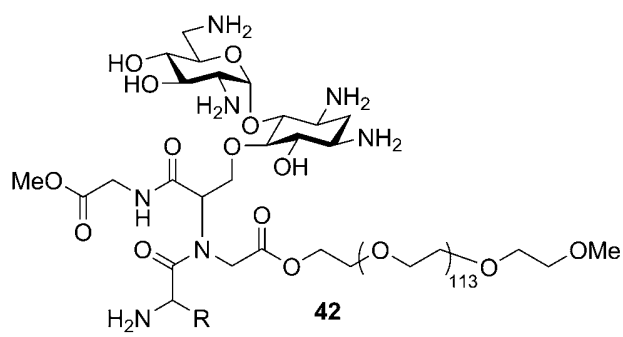


moiety was reacted with another aminoglycoside containing a free thiol to form the homo- or heterodimers.

Those compounds along with some naphthalene-based diimide conjugated bis-aminoglycoside compounds were investigated by Tok and co-workers for their ability to bind rRNA Asites and HIV-1 RRE (Figure 11). ${ }^{[32,33]}$ The entropic effects of linking the aminoglycosides lead to higher inhibitory activity than simply doubling the concentration of the parent aminoglycosides and also suggested multiple neomycin B binding sites in the RRE; this shows there is something to be gained from this strategy. Subsequently Decout and co-workers reported a series of neamine dimers and their affinity toward TAR RNA (Figure 12). ${ }^{[34]}$ These compounds showed good activity, inhibiting TAR-Tat binding at submicromolar concentrations.

Another series of neamine dimers has also been generated. ${ }^{[145]}$ The aminoglycoside dimers were tested for MIC values and translational inhibition, and were found to be in the low-micromolar and nanomolar ranges, respectively. Additionally, Dumas and co-workers coupled the neamine's $\mathrm{N} 1$ amine with various diacids including maleic acid, succinic acid, and malonic acid to form dimers. ${ }^{[146]}$ Though relatively few studies on bivalent aminoglycosides have been carried out thus far, they certainly could provide another avenue for the development of aminoglycoside chemotherapeutic agents that are selective for a particular target.

\subsection{Aminoglycoside-small- molecule conjugates}

The appending of various chemical functionalities to known aminoglycosides is another popular strategy aimed at developing improved aminoglycoside-based drugs. Although this strategy has proved incredibly fruitful, there are still a number of hurdles that must be surmounted, not the least of which is our ability to predict and achieve target selectivity while maintaining potency.

In 2005, the synthesis and biological testing of a large series of 2,5-dideoxystreptamine derivatives were reported (Figure 13). ${ }^{[147]}$ These series of O6ether, O6-acetamide, and N1-de-

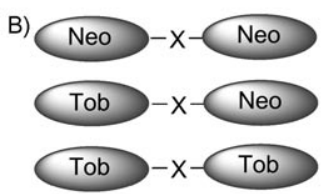

rivatives generally showed some antibacterial activity, yet none of the designed compounds surpassed the respective parent compounds in terms of IC 50 or MIC values. As the authors note, this study exemplifies the sensitivity to modification of natural aminoglycosides and the difficulty of enhancing compounds that Nature has spent thousands of generations optimizing. Nonetheless, other efforts have quite successfully yielded large numbers of active compounds such as the series of $\mathrm{C2}^{\prime \prime}$ ether analogues of paromomycin that were recently reported by $\mathrm{Ha}$ nessian and co-workers (Figure 14). ${ }^{[148]}$ This series, in contrast, yielded many analogues with equal or improved activity to the parent compound against a susceptible $S$. aureus strain and possibly even reduced nephrotoxicity. The contrast in these two studies highlights how fickle aminoglycosides can be when it comes to modifications about their scaffold.

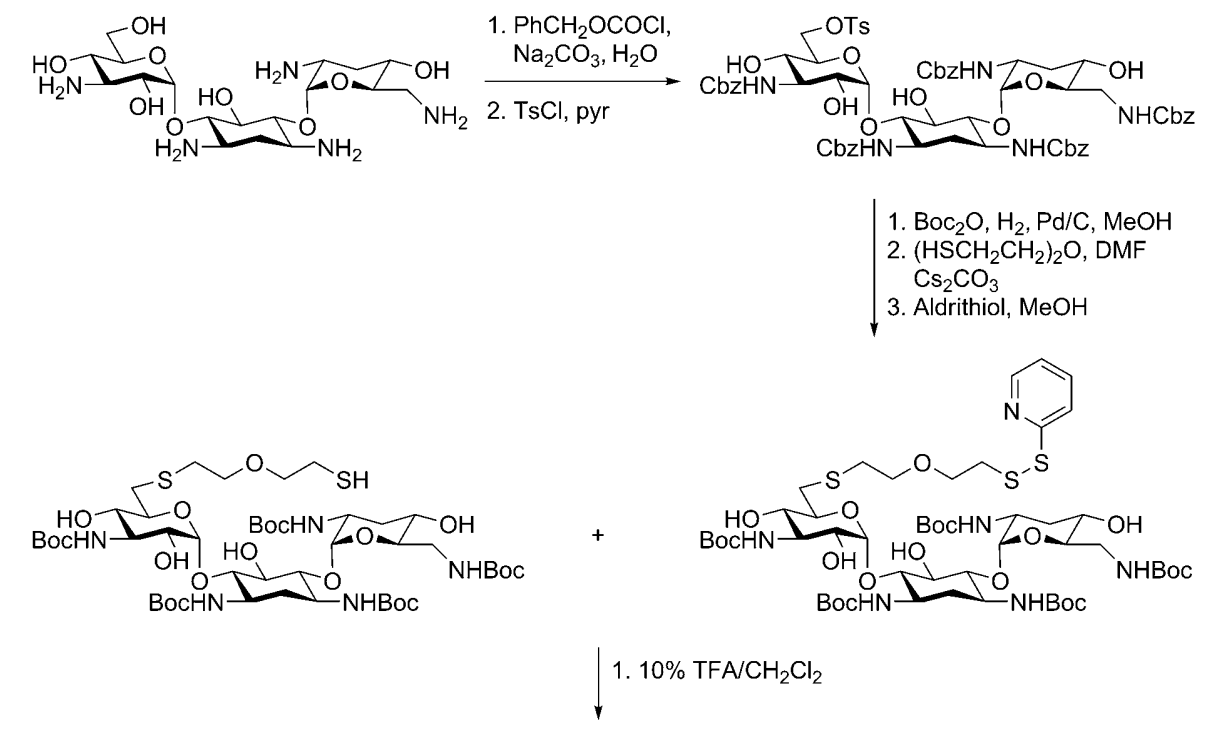

$$
\left(\stackrel{3}{x_{S}}\right.
$$

Scheme 6. Synthesis of disulfide-linked kanamycin dimers.
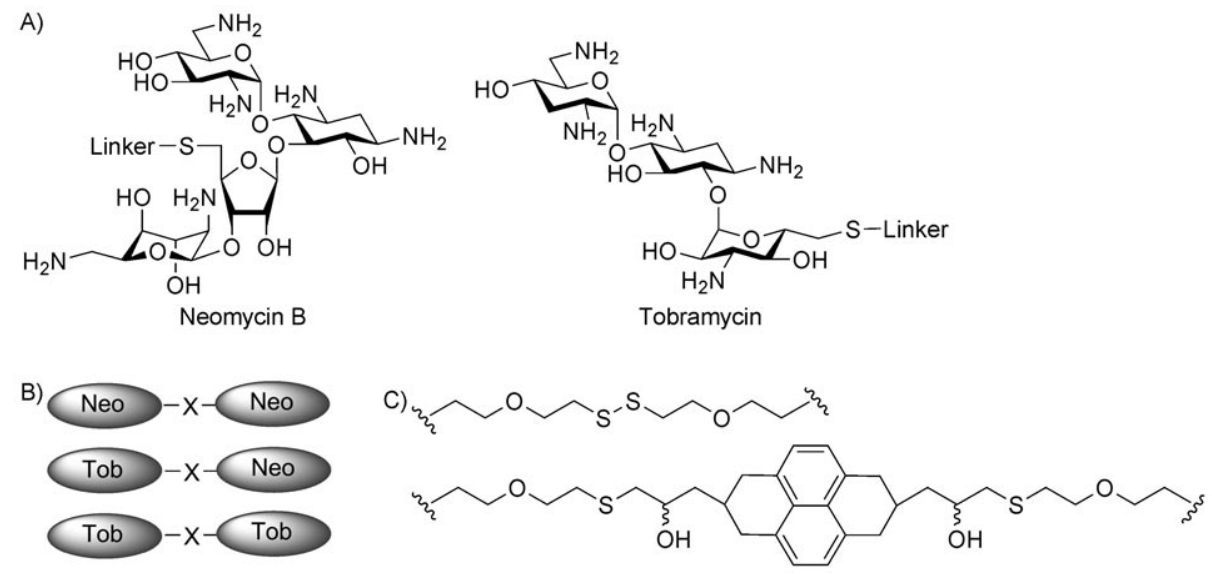

Figure 11. Structures of A) modified neomycin B and tobramycin with the linking position indicated, and B) a schematic illustration of aminoglycoside dimers synthesized and tested against HIV-1 RRE and rRNA A-sites. 
A)

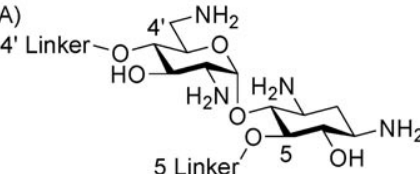

B)

Neamine ${ }^{4} \mathrm{O}_{-} \mathrm{R}^{-} \mathrm{O}^{4^{\prime}}$ Neamine

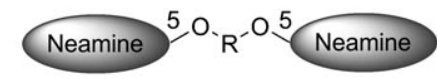

$\mathrm{R}=\mathrm{N}_{\mathrm{H}}^{\mathrm{O}}$

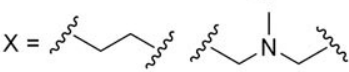

Figure 12. The 4'-4'- and 5-5-neamine dimers targeting HIV-1 TAR RNA.

A) Neamine was modified at the $4^{\prime}$ - or 5-hydroxy moiety to create B) a series of neamine dimers with two different linkers.

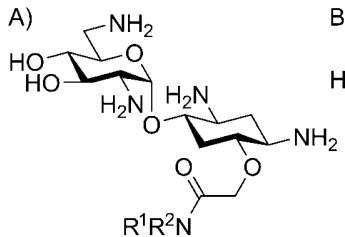

B)

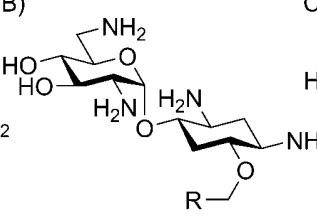

C)

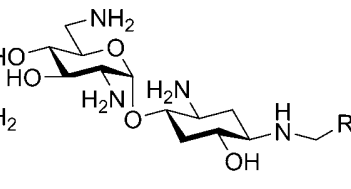

Figure 13. 2,5-dideoxystreptamine analogues designed towards the paromomycin and hygromycin B binding sites in helix 44 of bacterial rRNA. The A) O6-acetamide derivatives, B) O6-ether derivatives, and C) N1-derivatives were designed to include a variety of moieties such as sugars and other polar functionalities containing a high number of amine, hydroxyl, and/or heterocyclic groups.

This point is further emphasized by the work of Blount and Tor in which they developed novel nucleobase-aminoglycoside conjugates with selectivity towards the HIV-1 TAR over the prokaryotic A-site. ${ }^{[2]}$ With the goal of identifying novel aminoglycoside derivatives with selectivity towards the A-site, paromomycin and neomycin B were modified at the $5^{\prime \prime}$ - and $6^{\prime}$-positions to include a nucleobase, which eventually yielded compounds selective for HIV-1 TAR instead of the A-site (Figure 15). This fortuitous discovery showed that although selectivity can be achieved, it is not always easy to control or predict.

The incorporation of arginine into the structures of aminoglycosides has resulted in some interesting compounds. Nea-

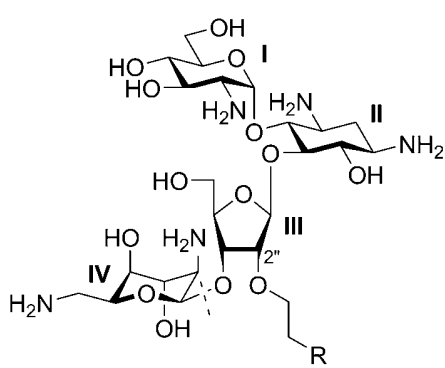

Figure 14. Paromomycin derivatives modified at the $\mathrm{C} 2$ " position to contain a number of various ether-linked functionalities. Series of derivatives with ring IV removed were also tested. Most derivatives showed equal or improved potency against the bacterial strains tested. bases. mine was generated as a hybrid with arginine and/or pyrene. ${ }^{[149]}$ A neamine-arginine hybrid (RN), a neamine-arginine-pyrene trimer (PRN), and a neamine-pyrene hybrid (PCN) were generated. RN was found to bind 50 times better than neamine to HIV-1 TAR, whereas PCN bound 16 times better, and PRN bound three orders of magnitude greater than neamine. The compounds also bound to RRE better than neamine: RN 45-fold better, PCN approximately no change, and PRN had 60 -fold greater binding.

James and co-workers reported site-specific and per-arginine aminoglycoside conjugates of paromomycin, neamine, and neomycin B with the ability to bind HIV-1 RNAs. ${ }^{[150]}$ It was shown that per-arginine conjugates, and in particular the hexa-arginine neomycin $B$, bind to the bulge region of TAR with a higher affinity than RRE. Another study of these same compounds also provided insight into the mechanism of action of these compounds. The AArCs inhibit HIV-1 infection by interfering with the gp120-CXCR4 interaction; this shows that they play a role as inhibitors of viral entry to human cells as well as HIV-1 RNA binders. ${ }^{[151]}$

Another type of aminoglycoside conjugates, aminoglycoside-acridine conjugates, were synthesized and evaluated for their ability to selectively target the HIV-1 RRE. The series consisted of both kanamyci$\mathrm{n} \mathrm{A}$ and tobramycin with 9-aminoacridine incorporated at the $6^{\prime}$-amine with no linker, as well as a series of neomycin B derivatives with 9-aminoacridine tethered at the $5^{\prime \prime}$-position by various linkers (Figure 16). ${ }^{[152]}$ Neomycin B derivatives with the shortest linkers showed the highest RRE specificities, but were all surpassed by the tobramycin and kanamycin A derivatives, which were found to bind the Rev-RRE complex 100 to 1000 times better than the parent compounds, respectively.

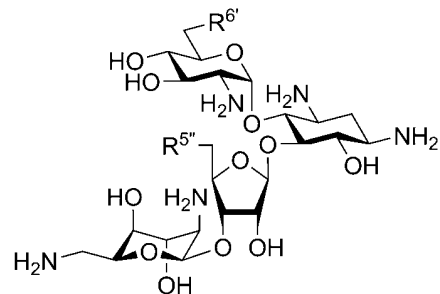<smiles>[R7]OC#[R]OC(=O)n1cnc2c(N)ncnc21</smiles>

Figure 15. Aminoglycoside-nucleobase conjugates engineered to target the A-site found to be selective towards HIV-1 TAR rather than the target. Neomycin $\mathrm{B}\left(\mathrm{R}^{5^{\prime \prime}}=\mathrm{OH} \mathrm{R}^{6^{\prime}}=\mathrm{NH}_{2}\right)$ and paromomycin $\left(\mathrm{R}^{5^{\prime \prime}}=\mathrm{R}^{6^{\prime}}=\mathrm{OH}\right)$ were modified at either the $5^{\prime \prime}$ - or $6^{\prime}$-position to include one of the five illustrated nucleo- 


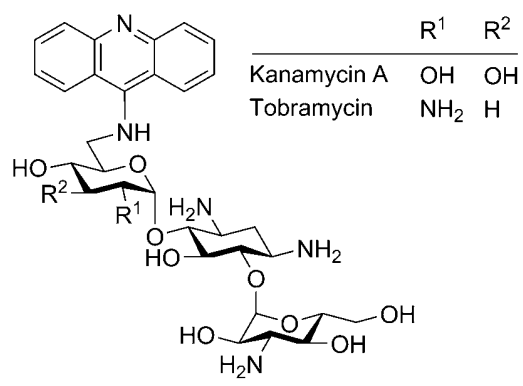

Figure 16. Aminoglycoside-acridine conjugates were synthesized and evaluated for selectivity towards HIV-1 RRE. The most selective toward RRE were the derivatized kanamycin $\mathrm{A}$ and tobramycin compounds depicted.

The recent development of aminoglycoside-fluoroquinolone hybrids highlights the potential of aminoglycoside hybrids as improved antibiotics. By chemically linking an aminoglycoside (neomycin B) to a fluoroquinolone (ciprofloxacin) through an optimized 1,2,3-triazole linker, Baasov and co-workers created compounds with significantly improved potency against Grampositive and Gram-negative strains of bacteria, compared to the parent compounds (Figure 17). ${ }^{[153]}$ It was shown that these

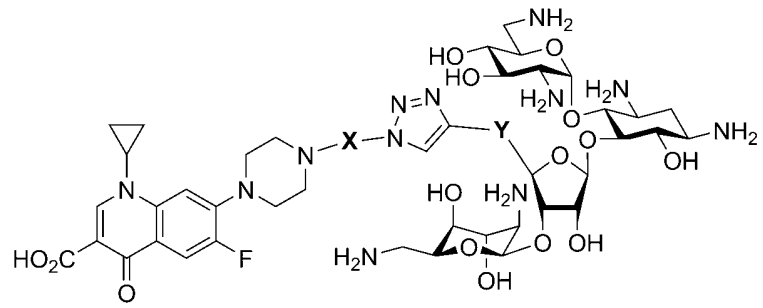

Figure 17. General structure of the ciprofloxacin-neomycin B conjugates designed as dual-action antibiotics. The compounds contain ciprofloxacin linked through a 1,2,3-triazole bridged linker to neomycin B. Nine ciprofloxacin derivatives were prepared with primarily aliphatic spacers $(X)$ containing a terminal azide. Three neomycin B derivatives were composed of an acetamide or ether-based spacer $(Y)$ that contained a terminal alkyne. Click chemistry was used to couple the various derivatives.

compounds demonstrate a balanced, dual-mode of action, inhibiting protein synthesis as well as the fluoroquinolone targets, DNA topoisomerase IV and DNA gyrase. Additionally, and perhaps more importantly, a case study of one ciprofloxacinneomycin B hybrid showed that it delayed the onset of resistance in both Gram-positive and Gram-negative strains compared to the single parent compounds or a 1:1 mixture of the respective parent compounds. This is an exciting advancement in the struggle to prevent the development of resistance to some of the most effective antibacterial agents currently available.

These advancements highlight both the difficulties that currently hinder the discovery of selective inhibitors as well as the exciting discoveries that can be the result of such efforts.

\section{New Tools and Recent Developments for Aminoglycosides' Investigation and Production}

\subsection{Investigation}

Once libraries of novel aminoglycosides have been generated, there is a need for technology that allows for high-throughput screening of compounds' interactions with RNA secondary structural elements as well as resistance-causing AMEs. Disney and co-workers are among those at the forefront of such technologies. Recently, they have developed microarray methods that allow for "interrogation" of such interactions among aminoglycosides and modified aminoglycosides in order to identify the factors that contribute to their affinity and selectivity for specific RNA targets (Figure 18). ${ }^{[154,155]}$ Additionally, the two-dimensional screening methods recently reported help to identify RNA hairpin loops that bind certain aminoglycosides and can also provide a means of probing general aminoglycosideRNA interactions. ${ }^{[156]}$ These studies will provide the groundwork and methodology necessary to facilitate rapid, rational design of novel aminoglycosides targeting specific RNA motifs.

Aminoglycoside derivatives and/or their coenzyme A cosubstrates have been used as structural and mechanistic probes to understand resistance enzymes. Auclair and co-workers have reported amide, phosphonate, and sulfonamide-linked aminoglycoside-CoA bisubstrates to probe $A A C\left(6^{\prime}\right)$ enzymes (Figure 19). ${ }^{[157-159]}$ Additionally, $6^{\prime}-\mathrm{N}$-acylated aminoglycosides have been applied as probes to study $A A C\left(6^{\prime}\right)$ and aminoglycosideRNA complexes. ${ }^{[160]}$ These studies have provided insight into the mechanistic details of resistance enzymes like AACs and structural features of aminoglycosides that dictate how bacteria avoid the action of aminoglycosides. They have undoubtedly provided valuable clues as to how researchers can "outwit" the bacteria's innate aminoglycoside-resistance mechanisms.

\subsection{Production}

Although it is clear that $\mathrm{N}$-acetylation of aminoglycosides by aminoglycoside $\mathrm{N}$-acetyltransferases (AACs) evolved as a mechanism of resistance in bacteria, there have been many reports of $\mathrm{N}$-acylated aminoglycosides, both natural and semisynthetic, that show a retention or even improvement in activity. ${ }^{[161-163]}$ $\mathrm{N}$-acetylation by AACs is a common means of deactivation in bacteria that results in decreased efficacy of the aminoglycoside (Section 3.1.3a). However, the semisynthetic $\mathrm{N}$-acylation with groups other than the normal acetyl has resulted in highly potent aminoglycosides. Adopting this approach led to the development of amikacin by N1-acylation of kanamycin with $\mathrm{AHB}_{,}{ }^{[161]}$ and arbekacin, which was produced by a combination of $3^{\prime}, 4^{\prime}$-dideoxygenation and N1-acylation. ${ }^{[162]}$ Although these advancements in aminoglycosides are exciting, the synthesis of the compounds is subject to the previously discussed pitfalls, making it difficult to generate a large number of novel compounds quickly and efficiently (Section 3.3). Current strategies aimed at circumventing this particular problem include 

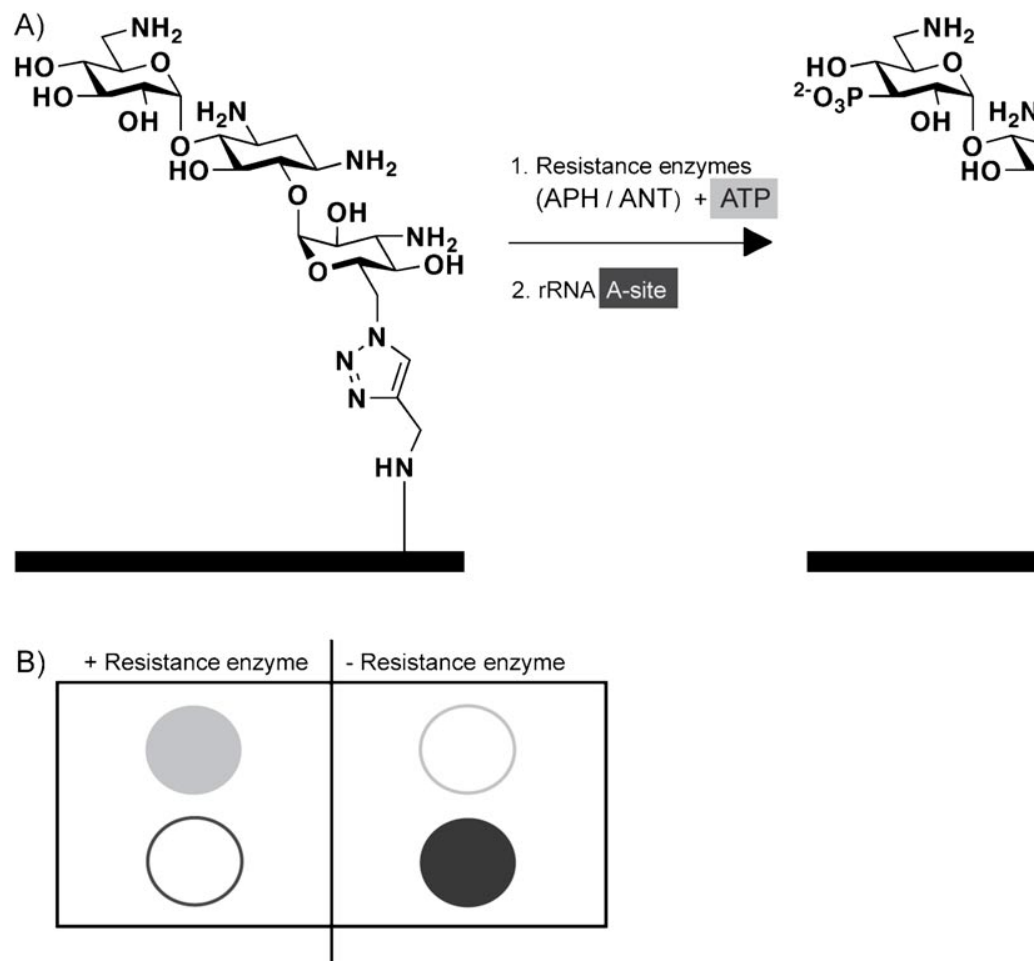

Figure 18. An antibiotic microarray-based method of studying resistance developed by Disney and co-workers. Libraries of aminoglycosides are arrayed and chemically attached to the microarray surface. A) Radioactive ATP is used as a substrate for AME, which transfers the radioactive tag. B) The arrays are then probed for binding to the target (shown is rRNA A-site) to see how binding is affected by the modification.

substrate promiscuity towards a number of aminoglycosides as well as acyl-CoA derivatives. The method allows for the generation of mono-acylated aminoglycosides as well as homo- and hetero-di-N-acylated aminoglycosides in quantities sufficient to screen each analogues' antibacterial potential. Thus, it is possible to decide which of the novel compounds show promising activity that is worth investigating on a larger scale all the while avoiding an arduous chemical synthesis that leads to a dead end.

Baasov and co-workers reported a similar, yet distinct chemoenzymatic approach to the development of novel acylated aminoglycoside derivatives in 2008. With the success of N1AHB-containing aminoglycosides in mind, they applied recombinant BtrH and BtrG enzymes involved in butirosin biosynthesis to selectively acylate the N1-position of a series of 2-deoxystreptamine containing pseudo-

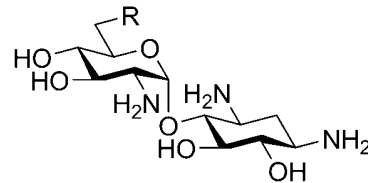

$R=A)$

B)<smiles>CNC(=O)CSCC(=O)O</smiles><smiles>CCNS(=O)(=O)CCSCCOC</smiles>

$n=1-4$

C)<smiles>[Y]P(=O)(OC)SCSCCO</smiles>

$\mathrm{X}=\mathrm{NH}, n=1-2$

$$
\mathrm{X}=\mathrm{O}, n=2
$$

Figure 19. A series of A) amide-, B) sulfonamide-, and C) phosphonatelinked aminoglycoside-coenzyme A bisubstrate analogues synthesized from neamine to studies enzymes involved in aminoglycoside resistance.

the application of enzymes to regiospecifically acylate an amine on the aminoglycoside scaffold.

Recently, S.G.-T. and co-workers reported a methodology that utilizes aminoglycoside $\mathrm{N}$-acetyltransferases and unnatural acyl-CoA analogues to chemoenzymatically generate $\mathrm{N}$-acylated aminoglycosides (Scheme 8). ${ }^{[163]}$ Two AACs, (AAC(6')-APH(2") and $A A C(3)-I V)$ were used, and both enzymes showed diverse di- and trisaccharide aminoglycosides by using a synthetic acy donor. ${ }^{[164]}$ Similarly, Llewellyn and Spencer recently used the enzymes responsible for synthesizing butirosin B in S. aureus to generate amikacin from kanamycin $A$ and neokacin from neomycin $B$ (Scheme 7). ${ }^{[165]}$ As is the case when applying AACs to chemoenzymatically alter aminoglycosides, this method greatly reduces the synthetic workload required to make such compounds by purely synthetic methods. The first instance of aminoglycoside derivatives produced by heterologous expression in E. coli was recently reported by Sohng and co-workers. ${ }^{[166]}$ Though this is the first report, one can see the potential for metabolically engineered aminoglycoside derivatives as chemotherapeutics or intermediates for use in the production of such agents.

\section{Summary and Outlook}

The development of novel aminoglycoside conjugates as treatments for bacterial infections, HIV, and genetic disorders resulting from PTCs is an active and productive area of research. Current strategies are aimed at developing compounds that are selective for their respective targets while showing reduced toxicity. Nephrotoxicity and ototoxicity have always been a cause for concern when considering treatment with aminoglycosides. Strategies have been developed to alleviate these toxicities and recent advances suggest that co-administration with 


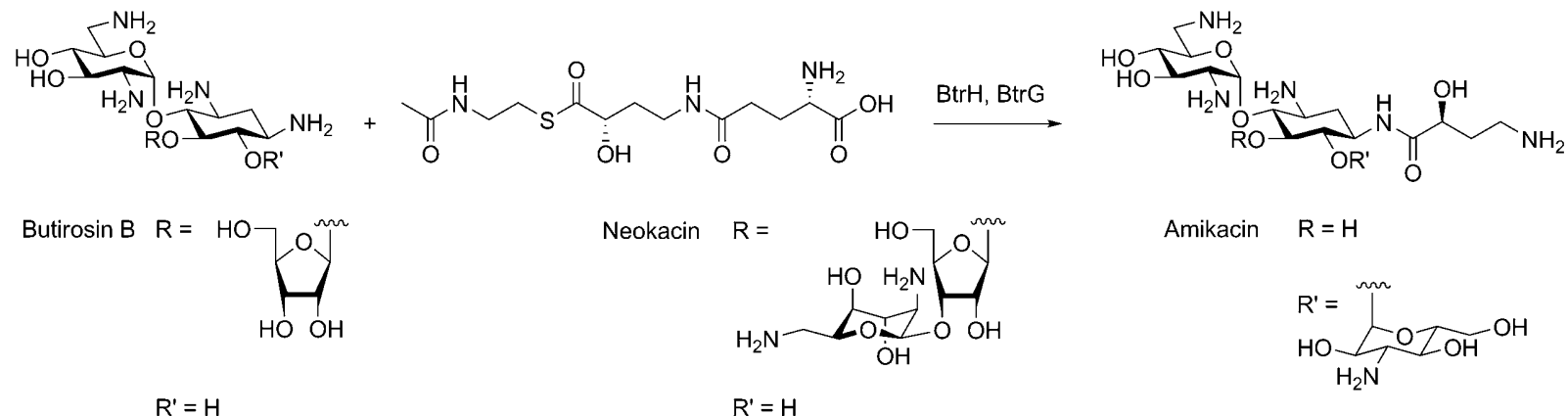

Scheme 7. Chemoenzymatic synthesis of the AHB modified aminoglycosides butirosin B, neokacin, and amikacin.

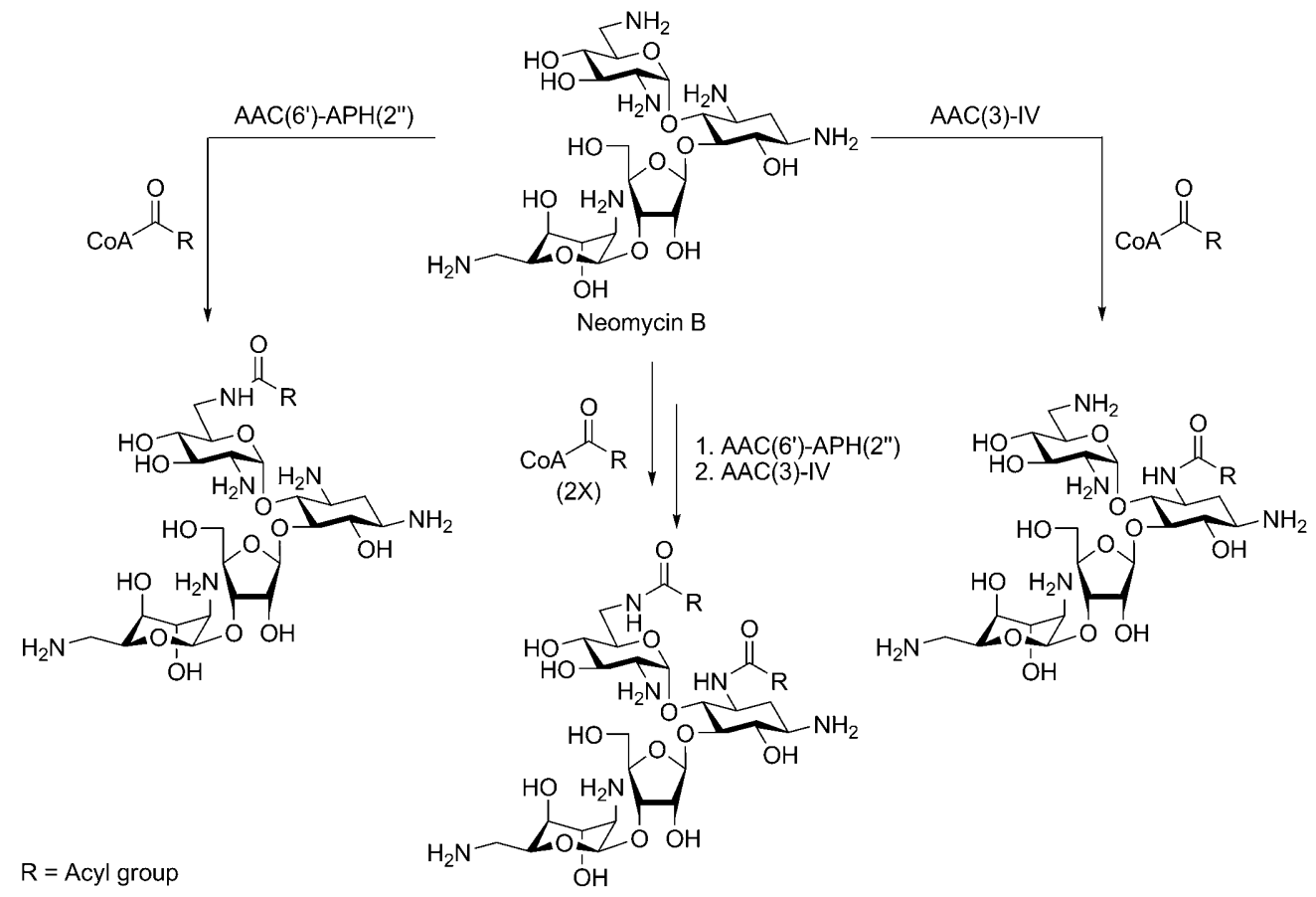

Scheme 8. A chemoenzymatic approach to the generation of monoacylated aminoglycosides as well as homo- and hetero-di-N-acylated aminoglycosides via two sequential acylations by aminoglycoside $\mathrm{N}$-acetyltransferases by using acyl-CoA as cosubstrates. Acceptable $\mathrm{R}$ groups include, but are not necessarily limited to acetyl-, propionyl-, 4-bromo-thiophene-2-carbonyl-, 6-fluoro-picolinyl-, glycinyl-, and malonyl-CoA.

a number of types of compounds might relieve many of the detrimental effects of aminoglycosides.

As a result of aminoglycosides' frequent clinical application, bacteria have evolved very efficient mechanisms of resistance that allow them to circumvent the action of these once formidable antibiotics. In response to this rapidly developing problem, a number of series of aminoglycoside derivatives have been identified/developed to combat resistant strains and even to combat the evolutionarily driven development of resistance. These hybrid or conjugate aminoglycosides represent a large step forward in the fight against aggressive pathogens that tend to develop resistance quickly.

The treatment of HIV-1 with aminoglycosides is still a relatively recent development, and even more so is the possibility of their preventative effects. The aim of many current research efforts is the identification of inhibitors selective for HIV-1 tar- gets over host targets as well as compounds with multiple targets. Although aminoglycosides show some promise as inhibitors of multiple interactions including the HIV-1 TAR and RRE complexes, the development of target-selective compounds remains a challenge. ${ }^{[28,29]}$ However, it seems a matter of time before efficacious aminoglycoside-based therapies are developed towards HIV-1, which is indeed a promising outlook.

Whereas total synthesis of aminoglycosides might be the best method of generating large amounts of material, the methods need improvement before quick and efficient syntheses can be achieved. Due to the number of reactions needed to generate aminoglycosides, many investigators have turned to chemoenzymatic reactions to generate novel aminoglycosides. The production of novel compounds continues to progress, thanks to chemoenzymatic and multicomponent condensation reactions and many chemists' willingness to put in the 
herculean effort necessary to synthesize novel compounds for testing, often without the benefit of structure-aided design.

To conclude, aminoglycosides, and most other antibiotics isolated from bacterial species, arose in response to selective pressure from, presumably, another bacterial species. As such, this class of antibacterial agents was designed by Nature to be very potent RNA-binding agents, which unfortunately leads to some toxicity in mammals, leading to apprehensive use in many places around the world. However, our current understanding of these compounds and their effect on biological systems is increasing rapidly and the authors believe that many of these problems are being, and will continue to be, addressed in the near future. A number of experts in the field have noted that by teasing out the various elements that lend selectivity towards either prokaryotic or eukaryotic RNA, we will begin to see decreased toxicity in humans treated with compounds directed at bacteria as well as increased selectivity of compounds designed to specifically target the eukaryotic ribosome for the treatment of genetic diseases. ${ }^{[20]}$ Resistance and toxicity are not likely to spell the end for aminoglycosides. Rather, they present a new challenge for researchers that once overcome will lead to aminoglycosides experiencing a renaissance in both the academic and clinical arena.

\section{Acknowledgements}

The authors would like to acknowledge the work on aminoglycosides of those not cited in this review due to the scope of the manuscript. The authors acknowledge the support of the Life Sciences Institute and the College of Pharmacy at the University of Michigan as well as a United States-Israel Binational Science Foundation (BSF), Jerusalem, Israel grant (2008017). J.L.H. is the recipient of an ACS Division of Medicinal Chemistry predoctoral fellowship sponsored by Eli Lilly.

Keywords: aminoglycosides - antibiotics - antiviral agents chemoenzymatic synthesis $\cdot$ drug resistance $\cdot$ genetic diseases

[1] J. Davies, G. D. Wright, Trends Microbiol. 1997, 5, 234.

[2] D. Moazed, H. F. Noller, Nature 1987, 327, 389.

[3] J. Kondo, K. Pachamuthu, B. François, J. Szychowski, S. Hanessian, E. Westhof, ChemMedChem 2007, 2, 1631.

[4] J. M. Ogle, V. Ramakrishnan, Annu. Rev. Biochem. 2005, 74, 129.

[5] S. Shandrick, Q. Zhao, Q. Han, B. K. Ayida, M. Takahashi, G. C. Winters, K. B. Simonsen, D. Vourloumis, T. Hermann, Angew. Chem. 2004, 116, 3239; Angew. Chem. Int. Ed. 2004, 43, 3177.

[6] Q. Vicens, E. Westhof, Biopolymers 2003, 70, 42.

[7] P. Pfister, S. Hobbie, Q. Vicens, E. C. Bottger, E. Westhof, ChemBioChem 2003, 4, 1078

[8] Q. Vicens, E. Westhof, Chem. Biol. 2002, 9, 747

[9] Q. Vicens, E. Westhof, J. Mol. Biol. 2003, 326, 1175.

[10] J. Kondo, B. François, R. J. Russell, J. B. Murray, E. Westhof, Biochimie 2006, 88, 1027

[11] Q. Vicens, E. Westhof, Structure 2001, 9, 647.

[12] B. François, R. J. Russell, J. B. Murray, F. Aboul-ela, B. Masquida, Q. Vicens, E. Westhof, Nucleic Acids Res. 2005, 33, 5677.

[13] G. Hirokawa, H. Kaji, A. Kaji, Antimicrob. Agents Chemother. 2007, 51, 175.

[14] M. Długosz, J. Trylska, J. Phys. Chem. B 2009, 113, 7322.

[15] H. Wang, Y. Tor, J. Am. Chem. Soc. 1997, 119, 8734.
[16] L. Jiang, D. J. Patel, Nat. Struct. Biol. 1998, 5, 769.

[17] S. N. Hobbie, P. Pfister, C. Bruell, P. Sander, B. François, E. Westhof, E. C. Bottger, Antimicrob. Agents Chemother. 2006, 50, 1489.

[18] S. N. Hobbie, P. Pfister, C. Brull, E. Westhof, E. C. Bottger, Antimicrob. Agents Chemother. 2005, 49, 5112.

[19] F. Walter, Q. Vicens, E. Westhof, Curr. Opin. Chem. Biol. 1999, 3, 694.

[20] J. Kondo, M. Hainrichson, I. Nudelman, D. Shallom-Shezifi, C. M. Barbieri, D. S. Pilch, E. Westhof, T. Baasov, ChemBioChem 2007, 8, 1700.

[21] S. B. Vakulenko, S. Mobashery, Clin. Microbiol. Rev. 2003, 16, 430.

[22] T. Hermann, Curr. Opin. Struct. Biol. 2005, 15, 355.

[23] R. J. Russell, J. B. Murray, G. Lentzen, J. Haddad, S. Mobashery, J. Am. Chem. Soc. 2003, 125, 3410.

[24] D. J. Cashman, J. P. Rife, G. E. Kellogg, Bioorg. Med. Chem. Lett. 2001 $11,119$.

[25] N. Venkataraman, A. L. Cole, P. Ruchala, A. J. Waring, R. I. Lehrer, O. Stuchlik, J. Pohl, A. M. Cole, PLoS Biol. 2009, 7, e95.

[26] A. Lapidot, A. Berchanski, G. Borkow, FEBS J. 2008, 275, 5236.

[27] R. Hegde, G. Borkow, A. Berchanski, A. Lapidot, FEBS J. 2007, 274, 6523.

[28] K. F. Blount, Y. Tor, ChemBioChem 2006, 7, 1612.

[29] K. F. Blount, F. Zhao, T. Hermann, Y. Tor, J. Am. Chem. Soc. 2005, 127, 9818.

[30] E. Ennifar, J. C. Paillart, S. Bernacchi, P. Walter, P. Pale, J. L. Decout, R. Marquet, P. Dumas, Biochimie 2007, 89, 1195.

[31] S. Bernacchi, S. Freisz, C. Maechling, B. Spiess, R. Marquet, P. Dumas, E. Ennifar, Nucleic Acids Res. 2007, 35, 7128.

[32] J. B. Tok, L. J. Dunn, R. C. Des Jean, Bioorg. Med. Chem. Lett. 2001, 11, 1127.

[33] J. B. Tok, J. Fenker, Bioorg. Med. Chem. Lett. 2001, 11, 2987.

[34] E. Riguet, J. Desire, O. Boden, V. Ludwig, M. Gobel, C. Bailly, J. L. Decout, Bioorg. Med. Chem. Lett. 2005, 15, 4651.

[35] D. W. Staple, V. Venditti, N. Niccolai, L. Elson-Schwab, Y. Tor, S. E. Butcher, ChemBioChem 2008, 9, 93.

[36] T. Jacks, M. D. Power, F. R. Masiarz, P. A. Luciw, P. J. Barr, H. E. Varmus, Nature 1988, 331, 280.

[37] M. J. Belousoff, B. Graham, L. Spiccia, Y. Tor, Org. Biomol. Chem. 2009 7, 30.

[38] L. Gorini, E. Kataja, Proc. Natl. Acad. Sci. USA 1964, 51, 487.

[39] R. Kellermayer, Eur. J. Med. Genet. 2006, 49, 445.

[40] M. Howard, R. A. Frizzell, D. M. Bedwell, Nat. Med. 1996, 2, 467.

[41] D. M. Bedwell, A. Kaenjak, D. J. Benos, Z. Bebok, J. K. Bubien, J. Hong, A. Tousson, J. P. Clancy, E. J. Sorscher, Nat. Med. 1997, 3, 1280.

[42] M. T. Howard, C. B. Anderson, U. Fass, S. Khatri, R. F. Gesteland, J. F. Atkins, K. M. Flanigan, Ann. Neurol. 2004, 55, 422.

[43] E. M. Welch, E. R. Barton, J. Zhuo, Y. Tomizawa, W. J. Friesen, P. Trifillis, S. Paushkin, M. Patel, C. R. Trotta, S. Hwang, R. G. Wilde, G. Karp, J. Takasugi, G. Chen, S. Jones, H. Ren, Y. C. Moon, D. Corson, A. A. Turpoff, J. A. Campbell, M. M. Conn, A. Khan, N. G. Almstead, J. Hedrick, A. Mollin, N. Risher, M. Weetall, S. Yeh, A. A. Branstrom, J. M. Colacino, J. Babiak, W. D. Ju, S. Hirawat, V. J. Northcutt, L. L. Miller, P. Spatrick, F. He, M. Kawana, H. Feng, A. Jacobson, S. W. Peltz, H. L. Sweeney, Nature 2007, 447, 87.

[44] S. M. Rowe, J. P. Clancy, BioDrugs 2009, 23, 165.

[45] I. Nudelman, A. Rebibo-Sabbah, M. Cherniavsky, V. Belakhov, M. Hainrichson, F. Chen, J. Schacht, D. S. Pilch, T. Ben-Yosef, T. Baasov, J. Med. Chem. 2009, 52, 2836.

[46] R. E. Hancock, S. W. Farmer, Z. S. Li, K. Poole, Antimicrob. Agents Chemother. 1991, 35, 1309.

[47] H. W. Taber, J. P. Mueller, P. F. Miller, A. S. Arrow, Microbiol. Rev. 1987 51, 439.

[48] R. E. Hancock, Annu. Rev. Microbiol. 1984, 38, 237.

[49] S. Magnet, J. S. Blanchard, Chem. Rev. 2005, 105, 477.

[50] L. E. Bryan, S. K. Kowand, H. M. Van Den Elzen, Antimicrob. Agents Chemother. 1979, 15, 7.

[51] M. H. Miller, S. C. Edberg, L. J. Mandel, C. F. Behar, N. H. Steigbigel, Antimicrob. Agents Chemother. 1980, 18, 722.

[52] N. Masuda, E. Sakagawa, S. Ohya, N. Gotoh, H. Tsujimoto, T. Nishino, Antimicrob. Agents Chemother. 2000, 44, 3322.

[53] M. Putman, H. W. van Veen, W. N. Konings, Microbiol. Mol. Biol. Rev. $2000,64,672$

[54] S. Shakil, R. Khan, R. Zarrilli, A. U. Khan, J. Biomed. Sci. 2008, 15, 5. 
[55] J. R. Aires, T. Kohler, H. Nikaido, P. Plesiat, Antimicrob. Agents Chemother. 1999, 43, 2624.

[56] S. Westbrock-Wadman, D. R. Sherman, M. J. Hickey, S. N. Coulter, Y. Q. Zhu, P. Warrener, L. Y. Nguyen, R. M. Shawar, K. R. Folger, C. K. Stover, Antimicrob. Agents Chemother. 1999, 43, 2975.

[57] S. Murakami, R. Nakashima, E. Yamashita, A. Yamaguchi, Nature 2002, 419, 587.

[58] E. W. Yu, J. R. Aires, H. Nikaido, J. Bacteriol. 2003, 185, 5657.

[59] R. Edgar, E. Bibi, J. Bacteriol. 1997, 179, 2274.

[60] Y. Doi, K. Yokoyama, K. Yamane, J. Wachino, N. Shibata, T. Yagi, K. Shibayama, H. Kato, Y. Arakawa, Antimicrob. Agents Chemother. 2004, 48, 491.

[61] J. W. Chow, Clin. Infect. Dis. 2000, 31, 586.

[62] M. Galimand, S. Sabtcheva, P. Courvalin, T. Lambert, Antimicrob. Agents Chemother. 2005, 49, 2949.

[63] J. J. Yan, J. J. Wu, W. C. Ko, S. H. Tsai, C. L. Chuang, H. M. Wu, Y. J. Lu, J. D. Li, J. Antimicrob. Chemother. 2004, 54, 1007.

[64] T. Powers, H. F. Noller, EMBO J. 1991, 10, 2203.

[65] L. P. Kotra, J. Haddad, S. Mobashery, Antimicrob. Agents Chemother. 2000, 44, 3249

[66] M. A. Zaunbrecher, R. D. Sikes, Jr., B. Metchock, T. M. Shinnick, J. E. Posey, Proc. Natl. Acad. Sci. USA 2009, 106, 20004.

[67] G. D. Wright, A. M. Berghuis, S. Mobashery, Adv. Exp. Med. Biol. 1998 456, 27.

[68] M. P. Mingeot-Leclercq, Y. Glupczynski, P. M. Tulkens, Antimicrob. Agents Chemother. 1999, 43, 727.

[69] C. Kim, D. Hesek, J. Zajicek, S. B. Vakulenko, S. Mobashery, Biochemistry 2006, 45, 8368

[70] V. Dubois, L. Poirel, C. Marie, C. Arpin, P. Nordmann, C. Quentin, Antimicrob. Agents Chemother. 2002, 46, 638.

[71] R. E. Mendes, M. A. Toleman, J. Ribeiro, H. S. Sader, R. N. Jones, T. R. Walsh, Antimicrob. Agents Chemother. 2004, 48, 4693.

[72] D. Centron, P. H. Roy, Antimicrob. Agents Chemother.. 2002, 46, 1402.

[73] K. S. Reece, G. J. Phillips, Gene 1995, 165, 141.

[74] D. A. Goldstein, B. Tinland, L. A. Gilbertson, J. M. Staub, G. A. Bannon, R. E. Goodman, R. L. McCoy, A. Silvanovich, J. Appl. Microbiol. 2005, 99, 7.

[75] A. M. Lovering, L. O. White, D. S. Reeves, J. Antimicrob. Chemother $1987,20,803$.

[76] A. Sunada, M. Nakajima, Y. Ikeda, S. Kondo, K. Hotta, J. Antibiot. 1999 $52,809$.

[77] K. Franklin, A. J. Clarke, Antimicrob. Agents Chemother. 2001, 45, 2238

[78] P. N. Rather, E. Orosz, K. J. Shaw, R. Hare, G. Miller, J. Bacteriol. 1993, $175,6492$.

[79] S. S. Hegde, F. Javid-Majd, J. S. Blanchard, J. Biol. Chem. 2001, 276, 45876.

[80] M. W. Vetting, S. S. Hegde, F. Javid-Majd, J. S. Blanchard, S. L. Roderick, Nat. Struct. Biol. 2002, 9, 653.

[81] L. E. Wybenga-Groot, K. Draker, G. D. Wright, A. M. Berghuis, Structure 1999, 7, 497

[82] E. Wolf, A. Vassilev, Y. Makino, A. Sali, Y. Nakatani, S. K. Burley, Cell 1998, 94, 439.

[83] B. T. Wimberly, D. E. Brodersen, W. M. Clemons, Jr., R. J. Morgan-Warren, A. P. Carter, C. Vonrhein, T. Hartsch, V. Ramakrishnan, Nature 2000, 407, 327.

[84] A. P. Carter, W. M. Clemons, D. E. Brodersen, R. J. Morgan-Warren, B. T. Wimberly, V. Ramakrishnan, Nature 2000, 407, 340.

[85] M. W. Vetting, S. Magnet, E. Nieves, S. L. Roderick, J. S. Blanchard, Chem. Biol. 2004, 11, 565

[86] M. L. Magãlhaes, M. W. Vetting, F. Gao, L. Freiburger, K. Auclair, J. S. Blanchard, Biochemistry 2008, 47, 579 .

[87] S. Magnet, T. Lambert, P. Courvalin, J. S. Blanchard, Biochemistry 2001, 40, 3700

[88] D. M. Daigle, D. W. Hughes, G. D. Wright, Chem. Biol. 1999, 6, 99.

[89] K. Radika, D. B. Northrop, J. Biol. Chem. 1984, 259, 12543.

[90] D. L. Burk, N. Ghuman, L. E. Wybenga-Groot, A. M. Berghuis, Protein Sci. 2003, 12, 426 .

[91] D. L. Burk, B. Xiong, C. Breitbach, A. M. Berghuis, Acta Crystallogr. Sect. D 2005, 61, 1273.

[92] K. A. Draker, D. B. Northrop, G. D. Wright, Biochemistry 2003, 42, 6565.
[93] M. W. Vetting, C. H. Park, S. S. Hegde, G. A. Jacoby, D. C. Hooper, J. S. Blanchard, Biochemistry 2008, 47, 9825.

[94] A. Robicsek, J. Strahilevitz, G. A. Jacoby, M. Macielag, D. Abbanat, C. H. Park, K. Bush, D. C. Hooper, Nat. Med. 2006, 12, 83.

[95] M. M. Neuhauser, R. A. Weinstein, R. Rydman, L. H. Danziger, G. Karam, J. P. Quinn, JAMA 2003, 289, 885.

[96] D. D. Boehr, S. I. Jenkins, G. D. Wright, J. Biol. Chem. 2003, 278, 12873

[97] S. Fujimura, Y. Tokue, H. Takahashi, T. Kobayashi, K. Gomi, T. Abe, T. Nukiwa, A. Watanabe, FEMS Microbiol. Lett. 2000, 190, 299.

[98] F. Javier Teran, M. Alvarez, J. E. Suarez, M. C. Mendoza, J. Antimicrob. Chemother. 1991, 28, 333.

[99] G. A. McKay, R. A. Robinson, W. S. Lane, G. D. Wright, Biochemistry 1994, 33, 14115

[100] G. A. McKay, P. R. Thompson, G. D. Wright, Biochemistry 1994, 33, 6936.

[101] S. Kondo, H. Yamamoto, H. Naganawa, H. Umezawa, J. Antibiot. 1972, 25, 483.

[102] W. C. Hon, G. A. McKay, P. R. Thompson, R. M. Sweet, D. S. Yang, G. D. Wright, A. M. Berghuis, Cell 1997, 89, 887.

[103] D. H. Fong, A. M. Berghuis, Antimicrob. Agents Chemother. 2009, 53, 3049.

[104] J. J. Siregar, S. A. Lerner, S. Mobashery, Antimicrob. Agents Chemother. 1994, 38, 641.

[105] K. Radika, D. Northrop, Anal. Biochem. 1984, 141, 413.

[106] J. J. Siregar, K. Miroshnikov, S. Mobashery, Biochemistry 1995, 34, 12681

[107] D. Nurizzo, S. C. Shewry, M. H. Perlin, S. A. Brown, J. N. Dholakia, R. L. Fuchs, T. Deva, E. N. Baker, C. A. Smith, J. Mol. Biol. 2003, 327, 491.

[108] P. G. Young, R. Walanj, V. Lakshmi, L. J. Byrnes, P. Metcalf, E. N. Baker, S. B. Vakulenko, C. A. Smith, J. Bacteriol. 2009, 191, 4133.

[109] J. W. Williams, D. B. Northrop, J. Biol. Chem. 1978, 253, 5908.

[110] L. C. Pedersen, M. M. Benning, H. M. Holden, Biochemistry 1995, 34, 13305.

[111] T. K. Desai, T. K. Tsang, Am. J. Med. 1988, 85, 47.

[112] G. B. Corcoran, D. E. Salazar, J. J. Schentag, Am. J. Med. 1988, 85, 279.

[113] P. Sander, T. Prammananan, E. C. Bottger, Mol. Microbiol. 1996, 22, 841

[114] B. Springer, Y. G. Kidan, T. Prammananan, K. Ellrott, E. C. Bottger, P. Sander, Antimicrob. Agents Chemother. 2001, 45, 2877.

[115] P. Pfister, M. Risch, D. E. Brodersen, E. C. Bottger, Antimicrob. Agents Chemother. 2003, 47, 1496

[116] P. Pfister, S. Hobbie, C. Brull, N. Corti, A. Vasella, E. Westhof, E. C. Bottger, J. Mol. Biol. 2005, 346, 467.

[117] T. Prammananan, P. Sander, B. A. Brown, K. Frischkorn, G. O. Onyi, Y. Zhang, E. C. Bottger, R. J. Wallace, Jr., J. Infect. Dis. 1998, 177, 1573.

[118] M. Hainrichson, I. Nudelman, T. Baasov, Org. Biomol. Chem. 2008, 6, 227.

[119] L. Chen, M. Hainrichson, D. Bourdetsky, A. Mor, S. Yaron, T. Baasov, Bioorg. Med. Chem. 2008, 16, 8940.

[120] R. Janknegt, Pharm. World Sci. 1990, 12, 81

[121] O. W. Guthrie, Toxicology 2008, 249, 91.

[122] R. A. Tange, Ziekenhuisfarmacie 1987, 3, 15.

[123] L. Hema Bindu, P. P. Reddy, Int. J. Audiol. 2008, 47, 702.

[124] S. C. Harvey, P. Skolnick, J. Pharmacol. Exp. Ther. 1999, 291, 285.

[125] S. H. Hong, S. K. Park, Y. S. Cho, H. S. Lee, K. R. Kim, M. G. Kim, W. H. Chung, Hear Res. 2006, 211, 46

[126] S. N. Hobbie, S. Akshay, S. K. Kalapala, C. M. Bruell, D. Shcherbakov, E. C. Bottger, Proc. Natl. Acad. Sci. USA 2008, 105, 20888.

[127] J. Kondo, E. Westhof, Nucleic Acids Res. 2008, 36, 2654.

[128] M. B. Carlier, G. Laurent, P. J. Claes, H. J. Vanderhaeghe, P. M. Tulkens, Antimicrob. Agents Chemother. 1983, 23, 440.

[129] M. P. Mingeot-Leclercq, P. M. Tulkens, Antimicrob. Agents Chemother 1999, 43, 1003.

[130] Y. Yu, A. J. Szczepek, H. Haupt, B. Mazurek, J. Biomed. Sci. 2009, 16, 79.

[131] S. Hanessian, R. F. Butterworth, T. Nakagawa, Carbohydr. Res. 1973, 26, 261

[132] S. Hanessian, R. Masse, M. L. Capmeau, J. Antibiot. 1977, 30, 893.

[133] S. Hanessian, T. Takamoto, R. Masse, J. Antibiot. 1975, 28, 835.

[134] S. Hanessian, J. M. Vatele, J. Antibiot. 1980, 33, 675.

[135] M. Mizuno, H. Matsumoto, K. Goto, K. Hamasaki, Tetrahedron Lett 2006, 47, 8831.

[136] W. A. Greenberg, E. S. Priestley, P. S. Sears, P. B. Alper, C. Rosenbohm, M. Hendrix, S.-C. Hung, C.-H. Wong, J. Am. Chem. Soc. 1999, 121, 6527. 
[137] J. H. Ford, M. E. Bergy, A. A. Brooks, E. R. Garrett, J. Alberti, J. R. Dyer, H. E. Carter, J. Am. Chem. Soc. 1955, 77, 5311.

[138] J. G. da Silva, M. A. Hyppolito, J. A. de Oliveira, A. P. Corrado, I. Y. Ito, I. Carvalho, Bioorg. Med. Chem. 2007, 15, 3624.

[139] M. Fridman, V. Belakhov, S. Yaron, T. Baasov, Org. Lett. 2003, 5, 3575.

[140] K. Tatsuta, Proc. Jpn. Acad. Ser. B 2008, 84, 87.

[141] N. Nishizono, V. Nair, Nucleosides Nucleotides Nucleic Acids 2000, 19, 283.

[142] B. Westermann, S. Dorner, Chem. Commun. (Cambridge) 2005, 2116.

[143] W. K. C. Park, M. Auer, H. Jaksche, C.-H. Wong, J. Am. Chem. Soc. 1996, 118,10150

[144] H. Wang, Y. Tor, Bioorg. Med. Chem. Lett. 1997, 7, 1951.

[145] S. J. Sucheck, A. L. Wong, K. M. Koeller, D. D. Boehr, K.-A. Draker, P. Sears, G. D. Wright, C.-H. Wong, J. Am. Chem. Soc. 2000, 122, 5230.

[146] A. Bodlenner, A. Alix, J. M. Weibel, P. Pale, E. Ennifar, J. C. Paillart, P. Walter, R. Marquet, P. Dumas, Org.Lett. 2007, 9, 4415.

[147] D. Vourloumis, G. C. Winters, K. B. Simonsen, M. Takahashi, B. K. Ayida, S. Shandrick, Q. Zhao, Q. Han, T. Hermann, ChemBioChem 2005, 6, 58.

[148] S. Hanessian, J. Szychowski, S. S. Adhikari, G. Vasquez, P. Kandasamy, E. E. Swayze, M. T. Migawa, R. Ranken, B. François, J. Wirmer-Bartoschek, J. Kondo, E. Westhof, J. Med. Chem. 2007, 50, 2352.

[149] K. Hamasaki, A. Ueno, Bioorg. Med. Chem. Lett. 2001, 11, 591.

[150] A. Lapidot, V. Vijayabaskar, A. Litovchick, J. Yu, T. L. James, FEBS Lett. 2004, 577, 415

[151] G. Borkow, V. Vijayabaskar, H. H. Lara, A. Kalinkovich, A. Lapidot, Antiviral Res. 2003, 60, 181

[152] N. W. Luedtke, Q. Liu, Y. Tor, Biochemistry 2003, 42, 11391.
[153] V. Pokrovskaya, V. Belakhov, M. Hainrichson, S. Yaron, T. Baasov, J. Med. Chem. 2009, 52, 2243.

[154] M. D. Disney, O. J. Barrett, Biochemistry 2007, 46, 11223.

[155] M. D. Disney, J. L. Childs-Disney, ChemBioChem 2007, 8, 649.

[156] D. J. Paul, S. J. Seedhouse, M. D. Disney, Nucleic Acids Res. 2009, 37, 5894.

[157] F. Gao, X. Yan, O. M. Baettig, A. M. Berghuis, K. Auclair, Angew. Chem. Int. Ed. 2005, 44, 6859.

[158] F. Gao, X. Yan, K. Auclair, Chem. Eur. J. 2009, 15, 2064.

[159] F. Gao, X. Yan, O. Zahr, A. Larsen, K. Vong, K. Auclair, Bioorg. Med. Chem. Lett. 2008, 18, 5518

[160] X. Yan, F. Gao, S. Yotphan, P. Bakirtzian, K. Auclair, Bioorg. Med. Chem 2007, 15, 2944.

[161] S. Kondo, K. Hotta, J. Infect. Chemother. 1999, 5, 1.

[162] H. Kawaguchi, T. Naito, S. Nakagawa, K. I. Fujisawa, J. Antibiot. 1972, 25,695 .

[163] K. D. Green, W. Chen, J. L. Houghton, M. Fridman, S. Garneau-Tsodikova, ChemBioChem 2010, 11, 119.

[164] I. Nudelman, L. Chen, N. M. Llewellyn, E.-H. Sahraoui, M. Cherniavsky, J. B. Spencer, T. Baasov, Adv. Synth. Catal. 2008, 350, 1682.

[165] N. M. Llewellyn, J. B. Spencer, Chem. Commun. (Cambridge) 2008, 3786.

[166] N. P. Kurumbang, K. Liou, J. K. Sohng, J. Appl. Microbiol. 2009; DOI: 10.1111/j.1365-2672.2009.04582x

Received: December 21, 2009

Published online on April 15, 2010 